\title{
THE CAUSAL EFFECT OF EDUCATION ON CHRONIC HEALTH CONDITIONS IN THE UK
}

\author{
Katharina Janke*, David W. Johnston**, Carol Propper***, and Michael A. Shields** \\ * Lancaster University \\ ** Monash University \\ *** Imperial College London
}

Revised version: 14th October 2019

\begin{abstract}
We study the causal impact of education on chronic health conditions by exploitng two UK education policy reforms. The first reform raised the minimum school leaving age in 1972 and affected the lower end of the educational attainment distribution. The second reform is a combination of several policy changes that affected the broader educational attainment distribution in the early 1990s. Results are consistent across both reforms: an extra year of schooling has no statistically identifiable impact on the prevalence of most chronic health conditions. The exception is that both reforms led to a statistically significant reduction in the probability of having diabetes, and this result is robust across model specifications. However, even with the largest survey samples available in the UK, we are unable to statistically rule out moderate size educational effects for many of the other health conditions, although we generally find considerably smaller effects than OLS associations suggest.
\end{abstract}

JEL Classifications: I14, I24, I26

Keywords: Education Reform; Chronic Illness; Causality 


\section{Introduction}

One of the most robust findings in the social sciences is the strong positive correlation between education and health status at all ages. Many potential pathways may explain the role that education plays in promoting better health. However, many models predict a positive association between education and health because the same observed and unobserved factors that determine educational attainment (e.g. parental socioeconomic position, genetic ability, time and risk preferences) also determine health at birth and the returns to investments in health. For this reason, establishing causality in the education-health relationship has received increasing research attention.

The most prominent strand of the economics literature exploits policy reforms that increased years of education, tracing the effect of these increases on various measures of health and healthrelated behaviours in adulthood. The most commonly studied reforms increased the minimum school leaving age (ROSLA reforms), progressively introduced in many countries. ${ }^{1}$ Many of these studies investigated the causal link between education and mortality. Others have examined measures of morbidity including biomarkers for certain chronic health conditions.

The results from this literature, however, are mixed, with considerable disagreement about the extent to which education and health are causally related. Many studies find evidence that the additional year of schooling induced by these reforms drove significant improvements for some health or health-related behaviours (e.g. Arendt, 2005; Lleras-Muney, 2005; Oreopoulos, 2006; Siles, 2009; Powdthavee, 2010; van Kippersluis et al., 2011; Kemptner et al., 2011; Lager and Torssander, 2012; Brunello et al., 2013, 2016; Crespo et al., 2014; Fischer et al., 2013; Fletcher, 2015; Li and Powdthavee, 2015; Davies et al., 2018; Barcellos et al., 2018). ${ }^{2}$ Other studies, sometimes using the same data but different model specifications or measures of health, report little or no evidence of a causal effect (e.g. Mazumder, 2008; Albouy and Lequien, 2009; Lindeboom et al., 2009; Jürges et al., 2013; Clark and Royer, 2013; Johnston et al., 2015; Siles, 2015; Meghir et al., 2018). ${ }^{3}$ To add to the confusion, several studies find different results by gender, which are difficult to reconcile with healthrelated knowledge and Grossman model efficiency-type arguments (e.g. Kemptner et al., 2011; Brunello et al., 2013; Gathmann et al., 2015). Two recent reviews also come to different conclusions. Galama et al. (2018) conclude that there appears to be a causal effect of education on mortality and

\footnotetext{
${ }^{1}$ Evidence from such reforms has now been provided for many developed countries including Australia, Canada, Denmark, France, Germany, Italy, the Netherlands, Norway, Sweden, the UK, and the US.

${ }^{2}$ Similarly, it has been found that the additional schooling induced by ROSLA reforms has positively affected cognitive abilities at older ages, such as memory and executive functioning (e.g. Banks and Mazzonna, 2012).

${ }^{3}$ These negative findings are all the more salient because ROSLA reforms have been shown to have substantially increased wages in several (though not all) countries. This is the case in the UK. See Harmon and Walker (1995), Oreopoulos (2006) and Grenet (2013).
} 
smoking but not on obesity, but only in some contexts, while Hamad et al. (2018) conclude that education has a causal effect on the majority of health outcomes.

Our contribution is to provide a comprehensive study of the causal link between education and a large set of prevalent chronic health conditions. Chronic conditions such as cardiovascular disease, diabetes, arthritis, back and neck pain, and mental health problems are the main cause of poor health and disability in the US (Bauer et al., 2014). Worldwide, the disease burden is shifting away from communicable to non-communicable diseases (Murray et al., 2012) with substantial implications for health care budgets. ${ }^{4}$ Many chronic conditions result from lifestyle decisions (tobacco use, physical inactivity, excessive alcohol consumption and poor diet), all of which are potentially affected by greater education (e.g. Lim et al., 2012; Lee et al., 2012). Thus understanding whether education is causally linked to these conditions is important. However, there is currently limited robust evidence, arising from considerable variation in empirical specifications, small sample sizes, the birth cohorts examined, and the measurement of health outcomes (Hamad et al., 2018). ${ }^{5}$

We address these issues by applying a consistent modelling approach to information on a wide range of chronic health conditions reported in the largest population-representative survey-based sample available in the UK. We exploit two education reforms that affected large parts of the population. The first is the 1972 raising of the minimum school leaving age from 15 to 16 years. ${ }^{6}$ It applied to cohorts born in or after September 1957 and affected around 25\% of this population. These were individuals who would otherwise have left school at age 15 and so this reform affected the lower end of the educational attainment distribution. The second reform is the large rise in British educational attainment that occurred around 1990. This rise is the outcome of a number of educational policy changes that we describe in more detail in Section 5. These changes allowed more 18-year olds to receive higher education (Devereux and Fan, 2011) and led to around a 1.5-year increase in average years of schooling within one decade. This reform affected individuals born beginning around 1970. It provided opportunities to individuals across a larger part of the educational attainment distribution than the 1972 ROSLA reform.

\footnotetext{
${ }^{4}$ For example, in England, the treatment and care of people with chronic disease accounts for an estimated $70 \%$ of total health and social care expenditure (Department of Health, 2010).

${ }^{5}$ Hamad et al. (2018) note that sample sizes in this literature range from 128 to 8,887,608 individuals, with a median size of 28,310 . Given access to national death records, the samples available to study the effect of education on mortality are much larger than those available to study morbidity outcomes.

${ }^{6}$ In 1947 the minimum school leaving age was increased from 14 to 15 , and a number of studies use this reform to identify education effects. We do not use the 1947 reform for two reasons. First, information about chronic health conditions is not asked consistently of respondents over the age of 65 in our data. Second, we have concerns about the extent to which the results can be generalised because of the timing of the reform. For example, it occurred just after the end of World War 2 in a time of food rationing. Children born in the years around the cohort affected by the 1947 reform would have been different ages in the war and post-war years, and this could have differentially impacted on their future health.
} 
To derive causal estimates for the 1972 ROSLA reform we use a conservative fuzzy regression discontinuity approach similar to Clark and Royer (2013) with a tight 30-month bandwidth around this reform in order to close down the effect of time-varying changes that affect both education and health. We test robustness to even tighter band-widths. Identification from the second reform is less straightforward but we use a similar estimation strategy to that used by Bedard and Deschênes (2006) in which identification comes from across cohort covariation in education and chronic health conditions. We test the robustness of our results using the approach of Devereux and Fan (2011).

Our large nationally representative sample is from the UK Quarterly Labour Force Survey (QLFS) for 2001 to 2016. It contains around 5 million observations for those years and provides estimation samples in the relevant birth cohorts of around 360,000 observations for the first, and 425,000 observations for the second, reform. For the first reform, we observe individuals in the relevant birth cohorts between the ages of 41 and 61, of whom $36 \%$ report having a chronic health condition. For the second reform, we observe individuals between the ages of 30 and 50, of whom $27 \%$ report having a chronic health condition. These large samples, the high rates of chronic conditions and the adulthood age span of the cohorts allow us to also investigate whether the causal effect of education for each reform differs by gender and whether education becomes more protective of health as individuals get older.

The QLFS provides details on 17 different types of chronic health conditions. While some of these conditions have been examined previously with UK data, there is very limited or no evidence available on others. One clear omission is musculoskeletal conditions. After minor illnesses such as the common cold, such conditions are the most common reason for workplace sickness absence, accounting for a quarter (around 34 million) of working days lost in the UK each year (ONS, 2017). Another omission is mental illness, which accounts for $11.5 \%$ of working days lost (15.8 million) each year in the UK and is the largest single cause of disability in most developed countries (Friederich, 2017). While both conditions may cause considerable pain and loss of normal daily functioning, these impacts may not be well reflected in differential mortality rates, and are thus not captured in studies estimating the causal impact of education health using mortality as outcome variable. Our main focus is on the prevalence of any chronic conditions and key groups of conditions, including cardiovascular diseases, diabetes, musculoskeletal conditions, respiratory diseases, and mental illness, but we also provide estimates separately for the 17 types of morbidities. For several of these other conditions there is also little evidence on the causal impact of education, including common respiratory-related and stomach/digestive conditions and less prevalent conditions relating to sight and hearing.

The QFLS is considerably larger than the two UK data sources commonly used in studies examining education and health, the Health Survey for England (HSE) and the General Household 
Survey (GHS). Nor is it possible to examine specific conditions using the UK Census data (used by Clark and Royer, 2013) as the Census asks individuals only whether they have a chronic condition, not what condition(s) they have. Two recent studies have examined the impact of the 1972 ROSLA reform using the larger sample available from the UK Biobank (Davies et al., 2018; Barcellos et al., 2018). However, these studies do not consider many of the conditions that we examine and they also use very different model specifications compared to our conservative approach for their main results. A potentially limiting issue with the Biobank data, in comparison with the QLFS, is that it comes from a sample of volunteers, with more educated people being over-sampled. Our contribution over existing UK studies is discussed in detail in Section 2.

Our key findings are that there is a statistically significant negative association between years of education and chronic ill health but the strength of any associations weakens considerably once we apply causal identification techniques. However, even with the largest survey sample available for the UK, the level of precision we can achieve means that we cannot rule out some educational effects, positive or negative. Only for self-reported diabetes, and perhaps cardiovascular disease, do we find statistically significant evidence that an extra year of education has a beneficial effect on health (consistent with Davies et al. 2018). The finding for diabetes is present for both educational reforms, indicating that the effect of education on diabetes is present at different points in the education distribution. It is greater for males than females, but does not appear to increases as people age. Our findings are robust to a large set of tests.

The paper is organised as follows. Section 2 reviews the existing UK evidence on the causal impact of years of education on morbidity outcomes. Section 3 discusses our data. Section 4 presents our empirical approach and the results for the compulsory school reform. In Section 5 we present the results for the education expansion. Section 6 concludes.

\section{Existing UK evidence on the causal impact of education on health}

The UK literature has used the ROSLA reforms of 1947 (age 14 to 15) and 1972 (age 15 to 16) to aid causal identification within an IV/RDD approach. As in the wider international literature, these studies have produced mixed findings for the effect of education on chronic health conditions or biomarkers for chronic conditions. Siles (2009) exploits both reforms and uses pooled data from the 1980-2004 General Household Surveys (GHS) on around 200,000 individuals aged 25-60 born between 1915 and 1979. She finds that an extra year of education reduces the probability of reporting a long-term illness by around 5 percentage points (about 8 times larger than the OLS estimates). This finding is supported using an RDD around the two reforms $(n=47,344)$ and a 6-year cohort window around each reform. She argues that there is compelling evidence of a causal effect of education on health status. 
Several studies use pooled data from the Health Survey for England (HSE). The HSE has the advantage of collecting more detailed health information from respondents, including psychological measurement and biomarkers. The main limitation of the HSE is that, even if pooled over many annual surveys, it includes only a limited sample of the cohorts around the two reform dates. For the earlier of the two ROSLA reforms, Powdthavee (2010) uses data from 1991 to 2007 and finds that an extra year of schooling statistically significantly reduces the probability of adult hypertension (as measured by a nurse) by 7-10 percentage points for both men and women. But he finds no significant protective effect of education on hypertension after the 1972 reform. For both reforms the (lack of) data means wide windows are used, resulting in inclusion of cohorts born from 1926 to $1939(n=24,594)$ for the first reform and cohorts born 1952 to $1965(\mathrm{n}=34,559)$ for the second. Jürges et al. (2013) analyse pooled data from 1993 to 2006. They find no statistically significant effects on biomarkers relevant for heart disease (C-reactive protein and blood fibrinogen) using either the 1947 or 1972 reforms. However, even using an 8-year cohort window around each reform, their estimation samples have only 3,000 respondents.

Clark and Royer (2013) use two data sources and also study both reforms. Their first dataset, counts from the 2001 Census, has two self-reported measures of health: a self-assessed rating of health as good, fair, or bad, and a binary indicator of having a limiting chronic condition. No information on types of limiting health conditions is collected. They analyse aggregated data by month of birth cohort and apply tight bandwidths (15 to 55 months). However, due to the lack of information on education in the Census, only reduced-form estimates of the effect of education on health are provided. They find no statistically significant effect of education on the probability of having a limiting long-term illness using either the 1947 or 1972 reforms. They complement these estimates with IV estimates using data from the General Household Survey (GHS) (1986-1996) and the Health Survey for England (HSE) (1991-2004). Studying both reforms separately, they find some contradictory IV results. The 1947 reform yields a statistically significant positive effect of education on having a limiting chronic condition (0.046, $\mathrm{SE}=0.020$ ), while the corresponding estimate using the 1972 reform is 0.000 ( $\mathrm{SE}=0.038$ ). Pooling both ROSLA reforms and using individuals born between January 1920 and December 1969 to obtain a large sample, they find no evidence of a statistically significant causal relationship between education and health. They also provide IV estimates for having BMI>30, hypertension and blood pressure, but again find no statistically significant education effects. However, as they note, "the main limitation of the HSE data is that they include only a small sample of the population of interest (less than 1\%)". Their overall conclusion is that models that assume a causal effect of education on health may need to be rethought. 
Researchers have recently analysed data from the UK Biobank. Like the QLFS the Biobank has the advantage of a large sample that can examine the 1972 reform. A limitation is that it is a sample who volunteered. Consequently, the sample is better educated and healthier, which might impact on the extent to which any estimates can be generalised. ${ }^{7}$ Davies et al. (2018) look at the effect of the 1972 reform on a wide range of health measures using the data from the UK Biobank. They use data provided by 22,000 participants who turned 15 in the year before or after the 1972 reform (i.e. a 12month bandwidth). The main morbidity outcomes they study are whether an individual reports that they have ever been diagnosed by a doctor to have had: hypertension, a stroke, Type 2 diabetes, or a heart attack. Diagnosed cancers were collected from national cancer registries. Their measure of mental health is whether or not an individual reports ever having a whole week where they felt depressed or down. In contrast to our outcome variables that measure whether someone currently has a certain condition, the Biobank measures do not identify at what age individuals experienced the condition or whether they currently have it. For example, it is possible that an individual's experience of depression occurred in childhood or adolescence, before they completed their education. Davies et al. (2018) do not examine common musculoskeletal, respiratory, and digestive/stomach conditions, which our data allows, but they can examine a number of biomarkers: grip strength, BMI, blood pressure and arterial stiffness, each collected at some point between 2006 and 2010. Using a variety of reduced-form, regression discontinuity, and IV methods, they report consistent evidence across all estimation methods of a statistically significant causal effect of education for diabetes and mortality. ${ }^{8}$ They suggest that their mortality result might differ to the null result of Clark and Royer (2013) because their sample is around 10-years older, when more mortality has been observed.

More recently, Barcellos et al. (2018) also use Biobank data and the 1972 ROSLA reform to study the causal effect of education on health measures. They focus only on body size, lung functioning and blood pressure. Using a bandwidth of 20-years they find some evidence of a significant causal effect, particularly for individuals with a high genetic predisposition to obesity. Barcellos et al. (2019) further analyse this data and reform and find evidence that education reduces body size but increases blood pressure in middle age, with the reduction in body size being concentrated at the upper tail of the size distribution with a 7.5 percentage point reduction in obesity.

To our knowledge, the only paper that has used the large expansion in British educational attainment in the 1990s to identify the causal effect of education on health is James (2015). His

\footnotetext{
${ }^{7}$ It is unclear how the unrepresentativeness of the Biobank sample might bias the estimates. However, the authors suggest that it could attenuate their results towards the null (Davies et al., 2018).

${ }^{8}$ Davies et al. (2018) also find no evidence that the 1972 ROSLA reform 'experiment' was affected by genomic confounding.
} 
identification strategy relies on there being cohort-level changes in education and future health outcomes and thus being able to fully control for any confounders. James (2015) uses HSE data, pools the 1991-2012 annual surveys and restricts the sample to young adults aged 23 to 34, thus including cohorts born between 1962 and 1980, obtaining an estimation sample of around 30,000 respondents for the analysis of long-standing illness and 22,000 for the analysis of having a limiting illness. The results from the IV analyses are mixed. He finds that an additional year of education reduces the probability of having an early adulthood limiting illness by 5.7 percentage points but the estimated effect on having any long-standing illness is smaller and not statistically significant. He also finds that education reduces obesity but his estimates for self-assessed general health and having hypertension are statistically insignificant.

In summary, for the UK there appears to be little consensus on the question of whether there is a causal effect of education on later life health outcomes, particularly for morbidity (as distinct from mortality). There is also a lack of evidence for many of the most common chronic health conditions such as musculoskeletal and mental health conditions. As many studies have used the same data sets and analysed the same reforms, the diversity of results is even more salient. Thus, we believe that there is a need for additional evidence using the largest available nationally-representative samples to examine a wide range of chronic health conditions, at different points in the education distribution, in a unified estimation framework.

\section{The Data}

We use the UK Quarterly Labour Force Survey (QLFS), a nationally representative survey of households in the UK, and pool the data over 15 years (2001q3-2016q3). ${ }^{9}$ The QLFS is longitudinal, following respondents for up to 5 quarters. Our sample comprises approximately 5 million observations and 1.5 million individuals. We limit this sample to narrow age ranges around the reforms in order to reduce the effect of secular trends and aging. Even with these tight bandwidths, we have over 350,000 observations per reform. Appendix Table A1 shows the sample sizes, birth years, survey years, and summary statistics for each reform. The average age of respondents for Reform 1 (1972 ROSLA) is 50 (ranging from 41 to 61), while for Reform 2 (the Education Expansion) it is 40 (ranging from 30 to 50).

\footnotetext{
${ }^{9}$ We note that we are not the first study to use data from the QLFS to examine the causal link between education and health. Braakmann (2011) uses data from 1998 to 2002 on around 55,000 individuals born between 1957 and 1970, and uses being born in February (individuals who are about 3\% more likely to leave school with a qualification compared to those born one month earlier) as an instrument for education. Using this identification strategy, he finds no evidence of a significant causal effect of education for a variety of health measures.
} 
Although the QLFS is not primarily a health survey, it collects detailed information from respondents about chronic health conditions. Respondents are asked, "Do you have any health problems or disabilities that you expect will last for more than a year?" If they answer "yes", they are asked if this health problem affects the kind of paid work they might do, and if this health problem affects the amount of paid work they might do. Respondents are then given a list of 17 types of health problems from which they can select any number. Finally, they are asked if these health problems, when taken singly or together, substantially limit their ability to carry out normal day to day activities. The QLFS collects health information from proxy respondents (most often spouse or partner) when the household member is unavailable to be interviewed and around one-third of the sample are proxy observations. We expect that most respondents are aware of their spouse or partner's condition, and so we include in our main estimation sample health information provided by spouse or partner proxies. There is a high level of correspondence between self reports (at time $t$ ) and proxy reports (at time $t+1$ ), with consistency greater than $90 \%$ for nearly all health measures. In robustness tests we present results that exclude proxy responses.

For our main analyses we use all information we have on an individual's health, which is reported in up to 5 waves in the QLFS. As individuals age we expect that they will report more health conditions, but it is also the case that many health conditions can be treated, so that they are no longer considered a problem or disability or cured. In terms of stability, of those who ever report a condition, $59 \%$ report a condition in every wave, $28 \%$ report not having a condition at $t$ but having one at $t+1$ (new conditions), and 26\% report having a condition at $t$ but not at $t+1$ (treated or cured). Stability by condition type is highest for diabetes (75\% report in every wave) and epilepsy (70\%), and lowest for skin conditions (33\%), difficulty with seeing (38\%) and the catch-all category 'other' health problems (29\%). Around 50\% of respondents with musculoskeletal-related problems report them in all waves, which is around the same as for individuals reporting mental health conditions, chest or breathing problems, or cardiovascular-related problems. More details for each condition can be found in Appendix Table A2. We cannot rule out that some of the instability across waves is driven by misclassification. As we have no objective health information with which to compare the reports, it is impossible to determine what proportion of the across wave variation in health is valid. Our approach - to use all available health information in the QLFS - means we avoid the need to make strong assumptions regarding which responses are valid (e.g. using only Wave 1 observations). However, we test the robustness of our main results to redefining the outcome to have occurred only if an individual reports the health condition in every wave, thus only using one observation per individual. This set of alternative outcomes should capture more severe conditions. 
From the health information collected we construct a set of outcome variables. We define a dummy variable indicating whether the respondent has a chronic condition of any type, a dummy variable indicating whether a respondent has a limiting chronic condition, a dummy variable for each of the 17 chronic conditions, and a count variable summing over the 17 dummy variables for the separate conditions. Appendix Table A1 lists the 17 chronic conditions and presents sample means for all health measures for both samples. Some $36.4 \%$ of Reform 1 respondents report having at least one health problem compared to $26.5 \%$ for Reform 2 respondents. ${ }^{10}$ There is a similar gap across the two samples in the reporting of at least one condition that is limiting (13.1\% compared to $8.5 \%$ ) and the total number of conditions (0.834 compared to 0.525$)$. This gap reflects the younger age of those affected by the second reform. The 17 conditions are presented in order of how common they are in the older sample. For that sample, the prevalence ranges from $11.3 \%$ who have neck or back problems to under $1 \%$ for epilepsy, severe or specific learning difficulties, and speech impediments. These rankings are similar, though not identical, for the younger sample.

The various conditions reported are not necessarily all medical diagnoses, but they may be symptoms of underlying medical problems. Therefore, an individual may report several symptoms that are correlated. The correlation coefficients across conditions for our combined sample are presented in Appendix Table A3. To account for the correlations we group the conditions into clusters. We first estimate orthogonal factors for the 17 condition dummy variables, separately for each reform sample to allow for changes in population health over time. This principal-component factor analysis identifies four factors for the Reform 1 sample and five for the Reform 2 sample. The factor loadings suggest a cluster of musculoskeletal conditions, a cluster of mental health conditions, a cluster of cardiovascular (CVD) and diabetic conditions, a cluster of neurological and sensory disorders and, for the Reform 2 sample, an additional cluster of allergies and breathing problems. For the Reform 1 sample we generate four new outcome measures with the predicted scores for the four condition clusters, using the scoring coefficients in Appendix Table A4. For the Reform 2 sample we generate predicted scores for the five condition clusters, using the scoring coefficients in Appendix Table A5. These predicted scores are indexes of a cluster of problems with mean zero and a standard deviation of one.

Using self-reported chronic conditions as the object of analysis raises the issue of reporting error. To self-report, individuals have to know that they have the condition and be willing to report it in the survey. If better educated individuals were more likely to recognise (or find out) that they have a condition and report it, such reporting error would bias our estimates away from finding a protective

\footnotetext{
${ }^{10}$ While our data covers the years 2001-16, we only use 2006-16 for the education expansion sample so that respondents are aged 30+ to allow for the onset of chronic conditions and so that the youngest cohort (born in 1975) will have completed their education.
} 
impact of education on chronic illness. However, the extent of potential reporting error will likely vary by condition type. For example, diabetes and hypertension typically require a diagnosis from a medical professional, so would be at greatest risk for the education effect being under-estimated. In contrast, it is harder to think of an extra year of schooling generating reporting bias for musculoskeletal problems such as chronic back or neck pain.

\section{Reform 1: Raising the minimum school leaving age}

In September 1972 the minimum school leaving age in Britain was raised from 15 to 16 years. This reform forced a significant proportion of students who previously would have left school at age 15 to attend for one extra year. Appendix Figure A1 demonstrates the effect of the reform by displaying the proportion of students leaving school at age $\geq 16$ years for each month-year of birth. It is clear from the figure that the reform induced a large increase in the proportion of individuals who stayed in school until age 16.

\section{Estimation approach}

We use a fuzzy regression discontinuity framework, largely following Clark and Royer (2013). This involves the estimation of a two-stage least squares model, with the instrumental variable being an indicator that the individual was born after 1st September 1957 (i.e. turned 15 years old after 1st September 1972). Following the literature, in all models we cluster the standard errors at the monthof-birth level. We report $95 \%$ confidence intervals.

In the first-stage equation, we estimate the effects of the reform on educational attainment:

$$
E_{i c t}=\alpha_{0}+\alpha_{1} D_{i c}+f\left(R_{i c}\right)+\mathbf{X}_{i c t}^{\prime} \alpha_{2}+\varepsilon_{i c t}
$$

where $E_{i c t}$ is the age at which individual $i$ born in cohort $c$ surveyed at time $t$ completed full-time education. The covariate set includes a binary variable indicating whether the individual was born after 1st September $1957\left(D_{i c}\right)$, a 'running' variable measuring month-year of birth $\left(R_{i c}\right)$, and a vector of exogenous characteristics $\left(\mathbf{X}_{i c t}\right)$. This vector includes a third-order polynomial in age, and dummy variables for gender, year of survey (2002-2016), quarter of survey, month of birth (Jan-Dec), and interactions between month-of-birth dummies and being born after 1st September 1957.

For our main results, we use individuals born up to 30 months before and up to 30 months after the 1st September 1957 birth date threshold (March 1955 to February 1960). This narrow window compared to many other morbidity studies is feasible because of the large sample size of the QLFS. 
We show our main results are robust to even tighter bandwidths. The function $f\left(R_{i c}\right)$ in Equation (1) is a linear function of month-year of birth $R_{i c}$ with different slopes on either side of the birth date threshold (local linear approach). Given the use of a narrow bandwidth, this function should adequately capture any relationship between month-year of birth and educational attainment (and later life health outcomes).

The estimated effect of the change in the minimum school leaving age on educational attainment $-\alpha_{1}$ from equation $(1)-$ is shown in Appendix Table A6 and equals $0.282(\mathrm{~F}$-statistic $=$ 62.54). This implies that the reform increased average years of education by 0.28 years (see top graph in Figure 1). This increase in years of education was primarily generated by a 21 percentage point increase in the proportion of students leaving school at age $\geq 16$ years. Appendix Table A6 also shows that the proportion of students obtaining General Certificate of Education Ordinary Levels (O-levels) increased by 4.5 percentage points. In contrast, the reform had near zero effects on leaving school at age $\geq 17$ years and obtaining A-level qualifications, which were taken two years after O-levels. Therefore, we can be confident that the reforms affected those individuals who were its intended focus. When splitting the sample by gender the same patterns emerge.

In the second-stage equation, we estimate the effect of educational attainment (defined as years of full-time education) on health:

$$
H_{i c t}=\beta_{0}+\beta_{1} E_{i c t}+g\left(R_{i c}\right)+\mathbf{X}_{i c t}^{\prime} \beta_{2}+u_{i c t}
$$

where $H_{i c t}$ is one of our outcome measures (either a binary, count or continuous variable) derived from the reported chronic health problems. As in Equation (1), $g\left(R_{i c}\right)$ is a linear function of month-year of birth with different slopes on either side of the threshold. Finally, in line with practice in the ROSLA literature, we also provide the reduced form estimates. These show the comparison of chronic health of those born before and after the reform.

\section{Results}

Figure 2 provides initial evidence on the likely causal effect of education by plotting the proportion of individuals with chronic health conditions by month of birth cohort within a 60-month window around the ROSLA reform, including before and after linear predictions. There is some indication of a discontinuity at the reform data for reporting any chronic health or disability and this is most evident for the CVD and diabetes cluster. In contrast, we see no clear break for number of conditions, musculoskeletal conditions, mental health conditions, or neurological and sensory conditions. 
The top section of Table 1 presents our main summary estimates for the ROSLA reform. These are the estimated effects of educational attainment on: the likelihood of reporting any chronic health problem or disability; the likelihood of reporting a limiting chronic health problem or disability; and the number of chronic conditions. We first present OLS estimates of the education effect for only those cohorts born prior to the reform. It is customary to undertake the OLS only on the pre-reform sample, as the association that is estimated is that which would have occurred in the absence of the reform. We then present OLS estimates for a reduced-form treatment indicator and 2SLS estimates. ${ }^{11}$

The OLS estimates suggest that education has (the expected) negative significant association with all morbidity measures. Estimates are large relative to the sample means. Increasing education by one year is associated with a reduction in the likelihood of reporting any chronic health problem or disability by 7.5 percentage points and a limiting health problem or disability by a similar 7.3 percentage points. The number of conditions reduces by 0.35 . For the comorbidity clusters, an extra year of education is associated with a 0.184 of a standard deviation lower factor score for having a musculoskeletal condition, a 0.128 lower score for mental health conditions and a 0.060 lower score for CVD and diabetes conditions, respectively. Only for neurological and sensory conditions do we find no association with education, but this might be expected as these types of conditions might be more genetic in nature and thus potentially less related to lifestyle factors.

In contrast, the reduced-form point estimates for the treatment indicator in column 2 suggest much smaller health returns to education. These coefficients are estimated with relatively small confidence intervals. The $95 \%$ confidence interval for the effect of education on having at least one chronic condition does not include large positive or negative effects [-0.016, 0.019]. This is also the case for having a limiting condition [-0.015, 0.015]. The only estimate that is statistically significant at the 5\% level is for the CVD and diabetes conditions cluster. For this condition cluster the confidence interval overlaps with the OLS point estimate.

The 2SLS point estimates in column 3 are also smaller than the OLS estimates and are similar to the reduced-form estimates in column 2. For reporting any chronic condition the estimate is 0.5 percentage points, 15 times smaller than the OLS estimate, and statistically insignificant. A similar sharp reduction in the point estimates is seen for having a limiting chronic condition (-0.073 to -0.001$)$ and the number of conditions (-0.347 to 0.019). However, even with the largest survey sample available in the UK, the 2SLS estimates are less precisely estimated than the OLS coefficients, so we cannot rule out substantive education effects (negative or positive). For example, the $95 \%$ confidence

\footnotetext{
${ }^{11}$ In Appendix Table A7 we present the results from Woolridge's (1995) endogeneity tests from the 2SLS regressions for our main morbidity measures. With the exceptions of mental health condition and the neurological and sensory condition clusters, we reject the null hypothesis of exogenous education.
} 
interval for the 2 SLS estimate for any chronic condition is $[-0.047,0.056]$ compared to $[-0.085,-0.064]$ for the OLS estimates. ${ }^{12}$

The bottom section of Table 1 presents the corresponding estimates for the chronic health condition clusters. In contrast to the OLS estimates, with the exception of the neurological and sensory cluster, the reduced-form estimates are smaller (and are also relatively tightly estimated). The 2SLS estimates provide evidence of a statistically significant causal effect only for the CVD and diabetes cluster, with an additional year of education estimated to reduce the cluster score by 0.147 of a standard deviation, with a confidence interval of $[-0.241,-0.053] .{ }^{13}$ For musculoskeletal conditions the point estimate is statistically insignificant, but the $95 \%$ confidence interval sheds doubt on any substantive protective effect of education [-0.029, 0.228]. For mental health, and neurological and sensory, clusters, the 2SLS estimates rule out effect sizes any larger than around 0.1 of a standard deviation.

\section{Robustness}

We examined robustness to exclusion of proxy responses and to a redefined health measure of having a health condition only if an individual reports it in all waves (which gives only one observation per individual). The 2SLS estimates are shown in column 1 of Appendix Tables A8 and A9 respectively. Overall, with the proxies excluded, the summary findings hold. There is no evidence to suggest a statistically significant education effect for reporting any chronic health condition, with the $95 \%$ confidence interval being similar [-0.037, 0.061] to the full sample estimate [-0.047, 0.056]. Again, only for the CVD and diabetes conditions do we find a statistically significant protective educational effect, with an additional year reducing the score by 0.2 of a standard deviation. The results are similar using the redefined health condition measures, with the estimate of -0.317 for the CVD and diabetes cluster being the only one that is statistically different from zero.

The large size of our sample allows us to explore robustness to different month-of-birth cohort bandwidths. Table 2 (using the full sample) explores the effect of increasing the window from 36 to 84 months. ${ }^{14}$ The results confirm those of Table 1 . No statistically significant effect of education is found for the three summary measures and a consistently statistically significant effect is found only

\footnotetext{
${ }^{12}$ Our IV findings for a health problem or disability of any type in Table 1 is similar to that of Clark and Royer (2013) for a limiting long-term illness (using the 1972 reform) in their Table 5A, Panel B. Their IV estimate for this outcome, using a bandwidth of 91 months, is 0.000 ( $\mathrm{se}=0.038)$.

${ }^{13}$ Note that if $f\left(R_{i c}\right)$ is instead a high-order (quartic) polynomial function, a statistically significant effect is again only found for the CVD \& diabetes cluster. Additionally, $p$-values adjusted for multiple hypothesis tests using the BonferroniHolm (Holm, 1979) method indicate that the reform-based estimate for CVD and diabetes is statistically significant at the $5 \%$ level: the corrected $p$-value for the 2SLS estimate equals 0.022 (compared with the unadjusted $p$-value of 0.005 ).

${ }^{14}$ We note that for large bandwidths it is less valid to model the effects of cohorts using a linear time trend. However, we retain the linear time trend because the aim of this table is to show the level of consistency in the estimates by changing the bandwidths rather than the model.
} 
for the CVD and diabetes conditions cluster. The estimated effects reduce in magnitude as the size of the bandwidth increases from $-0.187[-0.274,-0.099]$ using a 36-month window to $-0.081[-0.170$, 0.009] for the 84-month window. Counter to expectations, there is a statistically significant positive effect of education on having a musculoskeletal condition for some bandwidths.

Given the results for the CVD and diabetes conditions cluster, we test for heterogeneity of the effect by gender and age. We use the reduced form approach, i.e. an expansion of the specification reported in Table 1, column 2, so that we can compare (Section 5 below) across reforms. Column 1 of Table 3 shows that the protective effect of education is larger for men, with the difference in effect size between genders equalling around 2 percentage points. In contrast, we are unable to identify a statistically significant increase (or decrease) in the effect of education across the age range of the sample (age 41-61). This result holds when we allow for non-linear age effects.

Table 4 presents estimates for all 17 chronic condition categories. There is a clear pattern of association: nearly all of the OLS estimates (column 1) are negative and statistically significantly different from zero. In contrast, for nearly all health conditions, the reform-based estimates (reducedform and 2SLS) suggest a much weaker negative relationship. In terms of overlap, the $95 \%$ confidence intervals for the 2SLS estimates indicate that the effect of education on the musculoskeletal conditions are smaller than OLS estimates suggest. This is also the case for other common conditions such as respiratory conditions; depression, bad nerves or anxiety; stomach, liver, kidney or digestive problems; as well as for some less prevalent conditions. ${ }^{15}$ While most of the 2SLS estimates are not statistically significant, the IV estimate for diabetes is statistically different from zero, consistent with the CVD and diabetes cluster result in our main results of Table 1. Appendix Figure A2 provides visual evidence of this effect for diabetes around the ROSLA cutoff. The estimate implies that increasing educational attainment by one year reduces the likelihood of reporting diabetes by 3.6 percentage points with $95 \%$ $\mathrm{CI}=[-.058,-.014]$. This estimate is 5 times the size of the OLS estimate and is large in relation to the sample mean of $4.0 \% .{ }^{16}$ After adjusting for multiple hypothesis tests using the Bonferroni-Holm method, the $p$-values corresponding to the diabetes estimates in columns 2 and 3 equal 0.001 and 0.027 , respectively.

\section{Reform 2: Education Expansion}

\footnotetext{
${ }^{15}$ For example, the $95 \%$ confidence interval from the OLS regression for problems or disabilities with legs and feet is [$0.061,-0.045]$ compared to 2 SLS [-0.015, 0.038]. Similarly, the lower bound of the confidence interval for respiratory (chest or breathing) problems from the OLS estimate is -0.034 , which is around three times larger than the lower bound of the confidence interval for the 2SLS estimate (-0.013).

16 This result is very similar to Davies et al. (2018) using the Biobank data where the diabetes IV estimate is -0.036 relative to a mean prevalence of $3.0 \%$. The two other conditions with statistically significant coefficients (progressive illness and learning difficulties) are less common and have smaller point estimates. Progressive illness has an unexpected sign.
} 
During the early 1990s there was a large increase in educational attainment in the UK. Between 1988 and 1994 the proportion of young people entering institutions of higher education full-time increased from around 15\% to 33\% (Devereux and Fan, 2011). There were several simultaneous drivers of this expansion. First, there was a large increase in the supply of university (degree-level) places after the Further and Higher Education Act 1992 enacted changes in higher education funding and administration. The Act led 35 polytechnic institutions to become universities and to offer degree-level qualifications. Second, institutions of higher education were encouraged to increase their enrolments when the Government decided to reduce the amount of money paid to universities per student while simultaneously relaxing limits on student recruitment. Third, the school leaving (age 16) qualifications, known as Certificates of Secondary Education and O-Levels, were replaced in 1986 by the single General Certificates of Secondary Education. This change modified performance assessment and grading, effectively increasing the proportion of students attaining high-grade passes. In turn this encouraged students to stay in school beyond the compulsory leaving age of 16 (Blanden and Machin, 2004). Therefore this set of reforms affected both those who might have left school at the minimum school leaving age of 16 and those who progressed to finishing high school but who would not, before the reform, have entered tertiary education.

This increased participation in higher education can be seen in the higher average age at which QLFS survey respondents aged $\geq 30$ completed full time education, as shown in the bottom graph of Figure 1. This figure, and others like it in the literature, ${ }^{17}$ demonstrates the strong growth in educational attainment that began with cohorts born around 1970 and ended with cohorts born around 1976.

\section{Estimation approach}

We exploit this increase in education to estimate the effect of education on health. We model the relationship between the health of individual $i$ born in cohort $c$ surveyed at time $t\left(H_{i c t}\right)$ and the average educational attainment (age at which left full-time education) of $i$ 's cohort $\left(\overline{E A}_{c}\right)$ :

$$
H_{i c t}=\gamma_{0}+\gamma_{1} \overline{E A}_{c}+a_{c t}+h(c)+\mathbf{W}_{i c t}^{\prime} \gamma_{2}+v_{i c t}
$$

where $a_{c t}$ are age fixed-effects, $h(c)$ is a linear function of year of birth (cohort), and $\mathbf{W}_{i c t}$ includes dummy variables for gender, year of survey, quarter of survey, month of birth, and wave number. ${ }^{18}$

\footnotetext{
${ }^{17}$ See Blanden and Machin (2004), Devereux and Fan (2011), Machin et al. (2012) and James (2015).

${ }^{18}$ This approach is analogous to the methodology used by Bedard and Deschênes (2006) in their evaluation of the longterm health impacts of military service. In their study, birth-cohort-specific percentage of veterans is the main variable of interest, rather than birth-cohort-specific educational attainment as in Equation (3).
} 
We also include the unemployment rate experienced by different cohorts at age 18 in order to control for potential correlation between labour market conditions and the education expansion. ${ }^{19}$

Our primary parameter of interest in Equation (3), $\gamma_{1}$, is identified from across-cohort covariation in educational attainment and health. The validity of our modelling approach depends on whether important cohort health effects exist and are correlated with the across-cohort growth in educational attainment, after accounting for age and time fixed effects, a cohort-specific unemployment rate and a linear cohort trend. The cohort trend term will control for observable and unobservable time-invariant cohort-specific predictors of health, assuming that these factors evolve linearly across cohorts (Bedard and Deschênes, 2006). We also limit the potential for confounding cohort effects by restricting the included birth cohorts to a relatively narrow 10-year window (1966 to 1975). $\hat{\gamma}_{1}$ is little changed when we exclude the cohort trend term although standard errors are smaller. Moreover, the estimated education effects generated using the 2SLS approach outlined in Devereux and Fan (2011) are very similar to the $\hat{\gamma}_{1}$ figures we present. Admittedly, we need to be more cautious in making causal statements from this model, as compared to the well-established identification strategy for the ROSLA reform. But it is reasonable to expect that if education is important in explaining health outcomes, it would be seen from the 1.5-year average increase in schooling that occurred over the 10-year cohort as shown in Figure 1.

\section{Results}

We first present the estimated education effects of this second reform on the likelihood of reporting any chronic condition, reporting a limiting condition, and the total number of conditions. The top panel of Table 5 presents the OLS association in column 1 and the reform-based estimates in columns 2 to 4. These test the robustness of the specification by adding a linear function of month-year of birth in column 3 and the national unemployment rate at school leaving age in column 4. Table 5 shows patterns that are similar to those for the ROSLA Reform. The estimated OLS coefficients clearly suggest that education statistically significantly reduced morbidity while the reform-based estimates are generally smaller and close to zero. The magnitudes of the OLS associations are smaller than those in Table 1, probably driven by the sample's younger age and thus lower frequency of chronic health conditions. For the most comprehensive model in column 4 we find smaller effects for having at least

\footnotetext{
${ }^{19}$ The average educational attainment of $i$ 's cohort could be used as an instrumental variable for $i$ 's educational attainment in a 2SLS approach. The 2SLS estimates of the education effects are very similar to the estimates of $\gamma_{1}$ in Equation (3) because by construction the first-stage regression coefficient on average educational attainment is close to 1 . The estimates from this exercise are shown in column 1 in Appendix Table A10. The reason they differ slightly from our main estimates is that in these regressions we use proxy observations, which we did not use to calculate cohort average educational attainment.
} 
one limiting condition and for the number of conditions than the OLS results suggest (i.e. the confidence intervals do not overlap). The lower bounds of the $95 \%$ confidence intervals suggest that an additional year of education lowers the probability of having a limiting health condition by 1 percentage point (relative to a mean of $8.5 \%$ ) and reduces the number of such conditions by 0.028 (relative to a mean of 0.525 ). The lack of a strong relationship between education and having any chronic condition is also apparent in Figure 3, which shows the proportion of respondents with any chronic condition plotted by year of birth. The figure shows no clear evidence of a change in slope at any point in the sample window.

For the condition clusters reported in Table 5, we find evidence of a statistically significant protective effect of education only for the CVD and diabetes cluster, with an additional year estimated to reduce the score by 0.064 (column 4) with a $95 \% \mathrm{CI}$ of $(-0.124,-0.005)$. The statistical significance of this estimate remains after adjustment for multiple comparisons (adjusted $p$-value equals 0.027). The results also suggest a smaller protective effect of education on mental health than simple OLS would suggest, with a lower bound of the confidence interval of - 0.014 of a standard deviation.

For the CVD and diabetes cluster we also examine heterogeneity by gender and age. Column 2 of Table 3 presents these estimates. There is a statistically significant gender difference, with education having a stronger protective effect for men, while there is no change in the effect of education with age. Overall, the results are again similar to those for the ROSLA reform.

\section{Robustness}

Estimates for the sample where we drop proxy responses are shown in column 2 in Appendix Table A8. As for the ROSLA reform, it is only for the CVD and diabetes conditions cluster that there is evidence of a statistically significant effect of an extra year of education. The estimate equals -0.077 (significant at the $1 \%$ level) compared to -0.064 (1\% level) shown in Table 5 for the full sample. The CVD and diabetes conditions cluster effect is also evident when we use the redefined condition measures (column 2, Appendix Table A9).

As an alternative modelling strategy, we estimate the specification used by Devereux and Fan (2011). Our main approach uses a narrow range of birth years (10 years from 1966-1975) and a linear cohort function, while Devereux and Fan use a wider range of birth years (25 years from 1958-1982) and a quartic cohort function. We prefer to control for cohort effects by restricting the range of birth years rather than relying on a higher-order cohort function. We also prefer to omit individuals born in later cohorts to ensure that (almost) all our sample have finished their educational attainment, while Devereux and Fan include individuals born in 1982 and aged 25 years at measurement, some of whom may still be in education. The estimates from this modelling exercise - using a sample of close to 1 
million observations - in column 2 in Appendix Table A10 generally confirm our main results. In particular, we again find no effect of education on the probability of having a chronic health condition, with the confidence intervals ruling out large negative or positive effects [-0.032, 0.015]. We also find that education reduces the CVD and diabetes cluster score by 0.063 of a standard deviation [- $0.116,-$ $0.010]$.

Finally, Table 6 presents the estimates for all 17 chronic conditions. Consistent with the findings for the ROSLA reform cohort, there is a statistically significant positive OLS association between education and all condition types. This is not the case for the reform-based estimates. We do find some evidence of a causal effect of education for diabetes, where the reform-based estimates are around four times the size of the OLS estimates. ${ }^{20}$ However, the $p$-value after adjusting for multiple comparisons using the Bonferroni-Holm method equals 0.236.

\section{Conclusion}

There is a lack of information about the causal effect of education on chronic health conditions, despite the associated growing disease burden. To examine this, we exploit the largest available UK survey that collects information about chronic health conditions. For identification, we exploit two educational reforms. One is the 1972 ROSLA reform. The second is the large increase in attainment (about 1.5 years on average) in the educational distribution of the UK in the 1990s. Our samples are large. For the ROSLA reform we use a sample of 360,000 observations from a cohort born in a 60month window, while we use around 425,000 observations from a cohort born within a 10-year window for the education expansion reform. For the ROSLA reform we follow a conservative modelling approach that uses a narrow bandwidth around the reform date. For the education expansion reform identification comes from across cohort covariation in education and chronic health conditions. We undertake extensive robustness tests of our results.

Our findings are as follows. First, the OLS associations are considerably larger (i.e. more negative, indicating that poor chronic health is associated with lower education) than the causal estimates. While the causal estimates have large standard errors, for most of the summary measures and most of the condition clusters the lower bound of the $95 \%$ confidence interval does not contain the OLS estimate and is often much smaller. For both reforms, we find no statistically significant effect of an additional year of education on any of our three summary measures: the probability of having a chronic health conditions; having a limiting chronic health condition; the number of chronic health conditions. For example, for the ROSLA reform the 2SLS estimate for any chronic condition is

${ }^{20}$ Appendix Figure A3 provides visual evidence for diabetes. 
0.005 with a $95 \%$ confidence interval of $[-0.047,0.056]$, relative to a sample mean of $36 \%$. For the education expansion reform, the corresponding estimate is $-0.003[-0.019,0.014]$, relative to the sample mean of $27 \%$. The results are generally robust to tightening the bandwidth around the ROSLA reform, including or excluding proxy responses, redefining the health measures, allowing for multiple hypothesis testing, and using a different specification for the educational expansion reform. However, with one exception, even with our large samples, we are unable to achieve very precise causal estimates, meaning that we are unable to rule out possible educational effects (positive or negative) for most of the summary measures, condition clusters and individual chronic health conditions we examine. $^{21}$

Second, we find a large degree of consistency in the results across the two different reforms, suggesting that neither the required extra year of schooling arising from the 1972 ROSLA nor the rise in education in the 1990s had a large effect on reductions in chronic health in adults affected by the reforms.

Third, when we examine specific comorbidity clusters, we find evidence of a significant protective effect of education on the CVD and diabetes cluster, but not for musculoskeletal, mental health, neurological and sensory, and allergies and breathing conditions. Using the ROSLA reform we find that an additional year of education is estimated to reduce CVD and diabetes by 0.147 [-0.241, 0.053] of a standard deviation and by 0.064 [-0.124, -0.005] using the educational expansion for identification. The protective effect of education for the CVD and diabetes cluster is stronger for males than females, but we find no evidence that this protective effect increases with age. When looking separately at the 17 different types of health condition reported in the QLFS, we find that it is diabetes that is driving this effect. The education expansion reform also suggests a strong protective effect of additional education for diabetes.

Our findings draw attention to the need to examine how education causally affects the onset and management of diabetes (and other highly lifestyle-related conditions). But they also demonstrate that any studies using retrospective data and conservative methods will require very large samples.

${ }^{21}$ This echoes Fletcher (2015) for the USA. 


\section{References}

Albouy, V. and Lequien, L. (2009). Does compulsory education lower mortality? Journal of Health Economics, vol. 28, pp. 155-168.

Arendt, JN. (2005). Does education cause better health? A panel data analysis using school reforms for identification. Economics of Education Review, 24, pp. 149-160.

Banks. J. and Mazzonna, F. (2012). The effect of education on old age cognitive abilities: Evidence from a regression discontinuity design. Economics Journal, vol. 122, pp. 418-448.

Barcellos, S., Carvalho, L. and Turley, P. (2018). Education can reduce health differences related to genetic risk of obesity. PNAS, vol. 115, pp. E9765-E9772.

Barcellos, S., Carvalho, L. and Turley, P. (2019). Distributional effects of education on health. NBER Working Paper 25898, May, Cambridge, US.

Bauer, U. E., Briss, P. A., Goodman, R. A., \& Bowman, B. A. (2014). Prevention of chronic disease in the 21st century: elimination of the leading preventable causes of premature death and disability in the USA. The Lancet, 384(9937), 45-52.

Bedard, K. and Deschênes, O. (2006). The long-term impact of military service on health: Evidence from World War II and Korean War veterans. American Economic Review, vol. 96, pp. 176194.

Blanden, J. and Machin, S. (2004), Educational inequality and the expansion of UK higher education. Scottish Journal of Political Economy, vol. 51, pp. 230-249.

Braakmann, N. (2011). The causal relationship between education, health and health related behaviour: Evidence from a natural experiment in England. Journal of Health Economics, vol. 30, pp. 753-763.

Brunello, G., Fabbri, D. and Fort, M. (2013). The causal effect of education on body mass: Evidence from Europe. Journal of Labor Economics, vol. 31, pp. 195-223.

Brunello, G., Foert, M. Schneeweis, N. and Winter-Ebmer, R. (2016). The causal effect of education on health: What is the role of health behaviours? Health Economics, vol. 25, pp. 314-336.

Clark, D. and Royer, H. (2013). The effect of education on adult health and mortality: Evidence from Britain. American Economic Review, vol. 103, pp. 2087-2120.

Crespo, L., López-Noval, B. and Mira, P. (2014). Compulsory schooling, education, depression and memory: New evidence from SHARELIFE. Economics of Education Review, vol. 43, pp. 3646.

Cutler, D. and Lleras-Muney, A. (2010). Understanding differences in health behaviors by education. Journal of Health Economics, vol. 29, pp. 1-18.

Cutler, D. and Lleras-Muney, A. (2012). Education and health: Insights from international comparisons. NBER Working Paper 17738, January.

Davies, N., Dickson, M., Davey Smith, G., van den Berg, G. and Windmeijer, F. (2018). The causal effects of education on health outcomes in the UK Biobank. Nature Human Behaviour, vol. 2, pp. 117-125.

Department of Health (2010). Improving the health and wellbeing of people with long term conditions. Leeds, UK.

Devereux, P. and Fan, W. (2011). Earnings returns to the British education expansion. Economics of Education Review, vol. 30, pp. 1153-1166.

Fischer, M., Karlsson, M. and Nilsson, T. (2013). Effects of compulsory schooling on mortality: Evidence from Sweden. International Journal of Environmental Research and Public Health, vol. 10, pp. 3596-3618.

Fletcher, J. (2015). New evidence on the effects of education on health in the US: Compulsory school laws revisited. Social Science and Medicine, vol. 127, pp. 101-107.

Friedrich, M. J. (2017). Depression is the leading cause of disability around the world. JAMA, 317(15), 1517-1517 
Galama, T., Lleras-Muney, A. and van Kippersluis, H. (2018). The effect of education on health and mortality: A review of experimental and quasi-experimental evidence. NBER Working Paper 24225, Cambridge MA.

Gathmann, C., Jürges, H. and Reinhold, S. (2015). Compulsory schooling reforms, education and mortality in twentieth century Europe. Social Science and Medicine, vol. 127, pp. 74-82.

Grenet, J. (2013). Is extending compulsory schooling alone enough to raise earnings? Evidence from French and British compulsory schooling laws. Scandinavian Journal of Economics, vol. 115, pp. 176-210.

Grossman, M. (1972). On the concept of health capital and the demand for health. Journal of Political Economy, vol. 80, pp. 223-255.

Grossman, M. (2008). The relationship between health and schooling. Eastern Economic Journal, vol. 34, pp. 281-292.

Hamad, R., Elser, H., Tran, DC., Rehkopf , DH. and Goodman, SN. (2018) How and why studies disagree about the effects of education on health: A systematic review and meta-analysis of studies of compulsory schooling laws. Social Science and Medicine, vol. 212, pp. 168-178.

Harmon, C. and Walker, I. (1995). Estimates of the economic return to schooling for the United Kingdom. American Economic Review, vol. 85, pp. 1278-1286.

Hex, N., Bartlett, C., Wright, D., Taylor, M., Varey, D. (2012) Estimating the current and future costs of Type 1 and Type 2 diabetes in the UK, including direct health costs and indirect societal and productivity costs, Diabetic Medicine, vol. 29, pp. 855-862.

Holm, S. (1979). A simple sequentially rejective multiple test procedure. Scandinavian Journal of Statistics, 65-70.

James, J. (2015). Health and education expansion. Economics of Education Review, vol. 49, pp. 193215.

Johnston, D., Lordan, G., Shields, M. and Suziedelyte, A. (2015). Education and health knowledge: Evidence from UK compulsory school reform. Social Science and Medicine, vol. 127, pp. 92100.

Jürges, H., Kruk, E. and Reinhold, S. (2013). The effect of compulsory schooling on health - evidence from biomarkers. Journal of Population Economics, vol. 26, pp. 645-672.

Kemptner, D., J Jürges, H. and Reinhold, S. (2011). Changes in compulsory schooling and the causal effect of education on health: Evidence from Germany. Journal of Health Economics, vol. 30, pp. 340-354.

King, H., Aubert. RE., Herman WH. (1998) Global burden of diabetes, 1995-2025: prevalence, numerical estimates, and projections. Diabetes Care, vol. 21, pp. 1414-1431.

Lager, ACJ. and Torssander, J. (2012). Causal effect of education on mortality in a quasi-experiment on 1.2 million Swedes. Proceedings of the National Academy of Science, vol. 109, pp. 84618466.

Lee, I-M., Shiroma, EJ., Lobelo, F., Puska, P., Blair, SN., Katzmarzyk, PT., for the Lancet Physical Activity Series Working Group. (2012). Effect of physical inactivity on major noncommunicable diseases worldwide: an analysis of burden of disease and life expectancy. Lancet, 380, pp. 291-229.

Li, J. and Powdthavee, N. (2015). Does more education lead to better health habits? Evidence from the school reforms in Australia. Social Science \& Medicine, vol. 127, pp. 83-91.

Lim, SS., Vos, T., Flaxman, AD., et al. (2012). A comparative risk assessment of burden of disease and injury attributable to 67 risk factors and risk factor clusters in 21 regions, 1990-2010 : a systematic analysis for the Global Burden of Disease Study 2010. Lancet, vol. 380, pp. 22242260.

Lindeboom, M., Llena-Nozal, A. and van der Klaauw, B. (2009). Parental education and child health: Evidence from a schooling reform. Journal of Health Economics, vol. 28, pp. 109-131. 
Lleras-Muney, A. (2005). The relationship between education and adult mortality in the United States. Review of Economic Studies, vol. 72, pp. 189-221.

Ma, Y., Nolan, A. and Smith, J. (2018). The value of education to health. Economics and Human Biology, 31, pp. 14-25.

Machin, S., Marie, O. and Vujić, S. (2012). Youth crime and education expansion. German Economic Review, vol. 13, pp. 366-384.

Mazumder, B. (2008). Does education improve health? A re-examination of the evidence from compulsory schooling laws. Economic Perspectives, vol. 2, pp. 2-16.

McCombie, L., Leslie, W., Taylor, R., Kennon, B., Sattar N. and Leanm M. (2017). Beating type 2 diabetes into remission. British Medical Journal, vol. 358, pp. j4030.

Meghir, C., Palme, M. and Simeonova, E. (2018). Education and mortality: Evidence from a social experiment. American Economics Journal: Applied Economics, vol. 10, pp. 234-256.

Mokdad, AH, Marks, JS, Stroup, DF. (2004). Actual causes of death in the United States, 2000. JAMA, vol. 291, issue 10, pp. 1238-1245.

Murray, CJL., Vos, T., Lozano, R., et al. (2012). Disability-adjusted life-years (DALYs) for 291 diseases and injuries in 21 regions, 1990-2010: a systematic analysis for the Global Burden of Disease Study 2010. Lancet, vol. 380, pp. 2197-2223.

Office for National Statistics (ONS, 2017). Sickness absence in the UK labour market: 2016. ONS: London, released 9th March 2017

Oreopoulos, P. (2006). Estimating average and local average treatment effects of education when compulsory schooling laws really matter. American Economic Review, vol. 96, pp. 152-175.

Powdthavee, N. (2010). Does education reduce the risk of hypertension? Estimating the biomarker effect of compulsory schooling in England. Journal of Human Capital, vol. 4, pp. 323-329.

Public Health England. (2014). Adult Obesity and Type 2 Diabetes https://www.gov.uk/government/uploads/system/uploads/attachment_data/file/338934/Adult obesity_and type 2_diabetes_.pdf

Siles, M. (2009). The causal effect of education on health: Evidence from the United Kingdom. Economics of Education Review, vol. 28, pp. 122-128.

Siles, M. (2015). The causal effect of schooling on smoking behaviour. Economics of Education Review, vol. 48, pp. 102-116.

Van Kippersluis, H., O’Donnell. O. and van Doorslaer, E. (2011). Long run returns to education: Does schooling lead to an extended old age? Journal of Human Resources, vol. 46, pp. 695-721. 
Figure 1: Age Left Full-Time Education by Month-Year of Birth
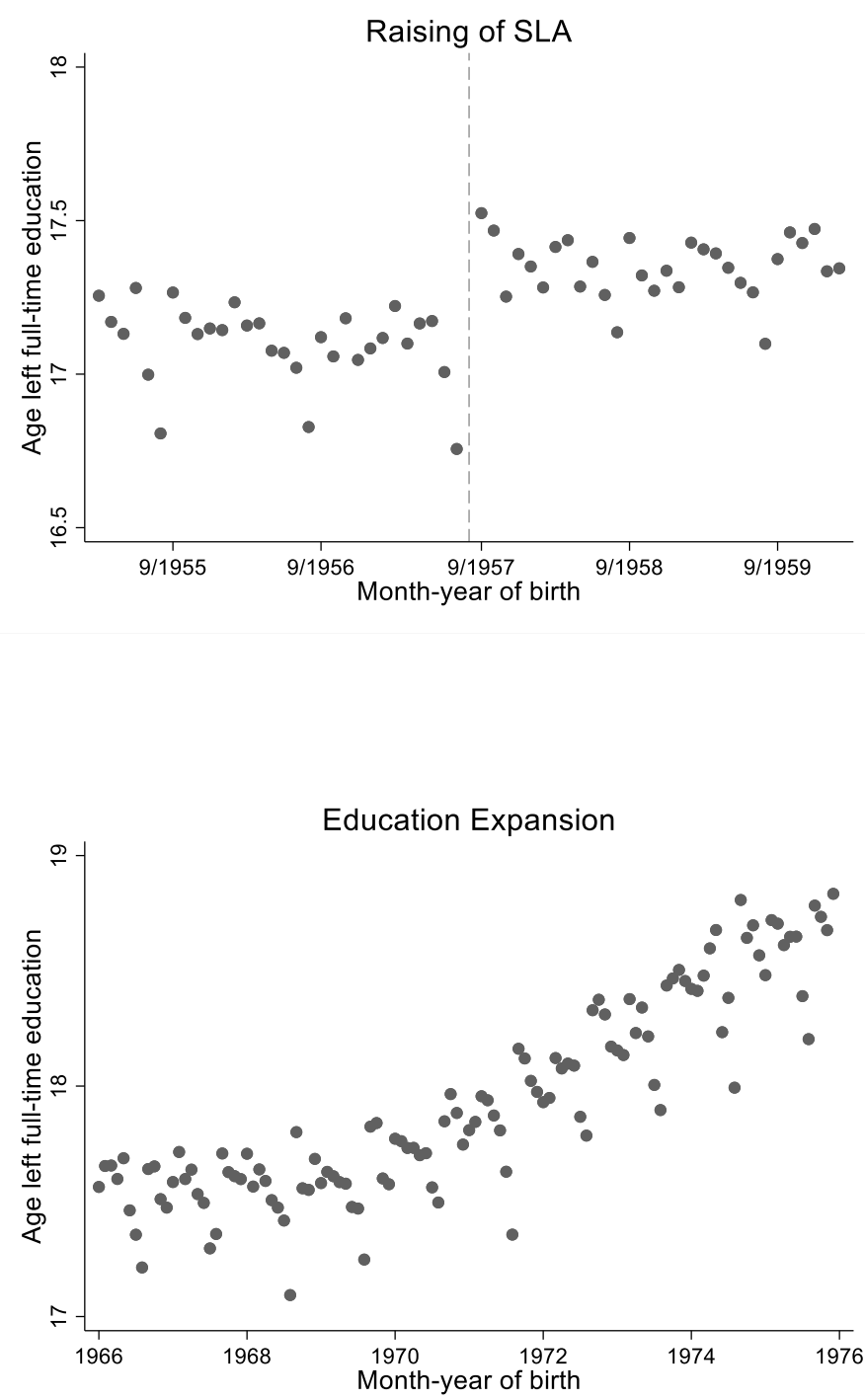

Notes: Each point represents the sample mean for a month-year of birth. 
Figure 2:

Prevalence of Chronic Conditions for Months-of-Birth around the ROSLA Reform Cutoff
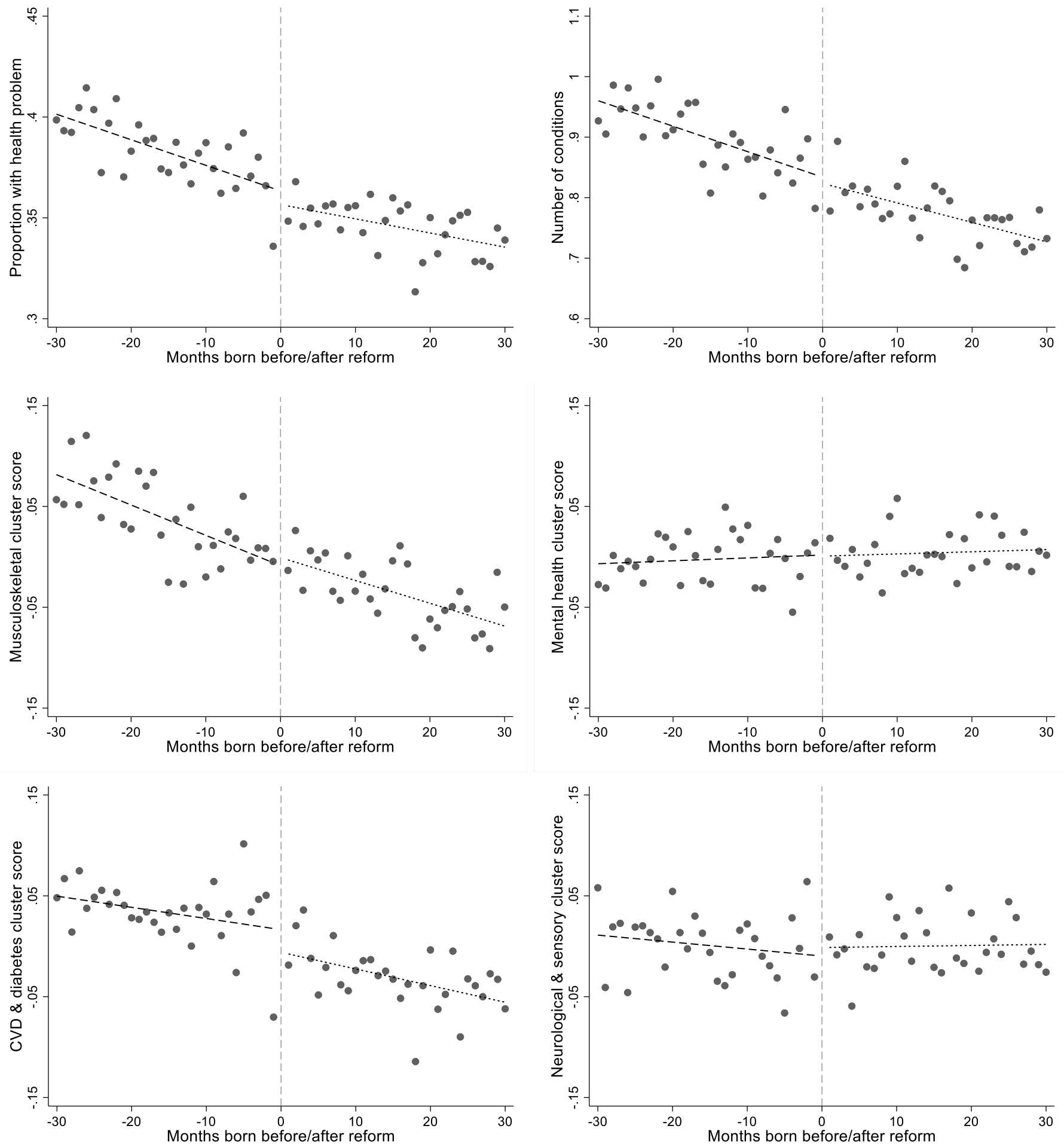

Notes: Each point represents the sample mean for a month-year of birth. Linear regression predictions from month of birth are calculated separately for months before and after reform. 
Figure 3:

Prevalence of Chronic Conditions for Months-of-Birth around the Education Expansion Reform

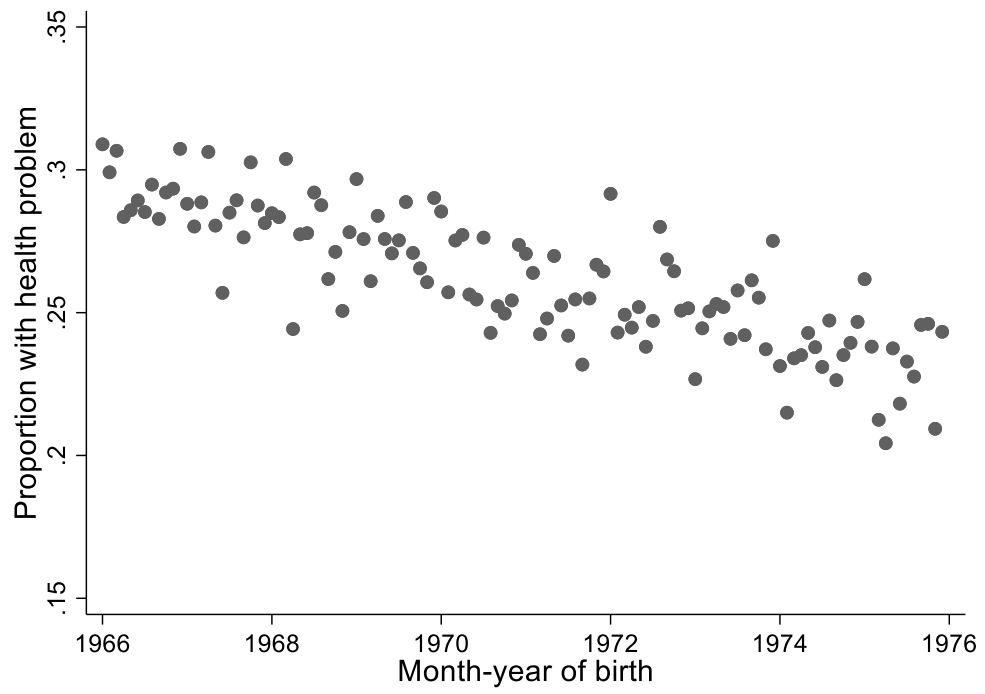

Notes: Each point represents the sample mean for a month-year of birth. 
Table 1:

ROSLA Reform: Estimates of the Impact of Age Completed Full-Time Education on Chronic Condition Summary Measures

\begin{tabular}{|c|c|c|c|}
\hline & $\begin{array}{c}\text { OLS } \\
\text { Age completed } \\
\text { education } \\
(1) \\
\end{array}$ & $\begin{array}{l}\text { OLS } \\
\text { Affected by } \\
\text { reform } \\
(2) \\
\end{array}$ & $\begin{array}{c}2 \text { SLS } \\
\text { Age completed } \\
\text { education } \\
(3) \\
\end{array}$ \\
\hline \multicolumn{4}{|l|}{ Summary Measures } \\
\hline At least one condition & $\begin{array}{c}-0.075^{* * *} \\
{[-0.085,-0.064]}\end{array}$ & $\begin{array}{c}0.002 \\
{[-0.016,0.019]}\end{array}$ & $\begin{array}{c}0.005 \\
{[-0.047,0.056]}\end{array}$ \\
\hline At least one limiting condition & $\begin{array}{c}-0.073^{* * *} \\
{[-0.083,-0.063]}\end{array}$ & $\begin{array}{c}-0.000 \\
{[-0.015,0.015]}\end{array}$ & $\begin{array}{c}-0.001 \\
{[-0.044,0.042]}\end{array}$ \\
\hline Number of conditions & $\begin{array}{c}-0.347^{* * *} \\
{[-0.390,-0.304]}\end{array}$ & $\begin{array}{c}0.006 \\
{[-0.037,0.050]}\end{array}$ & $\begin{array}{c}0.019 \\
{[-0.108,0.146]}\end{array}$ \\
\hline \multicolumn{4}{|l|}{ Condition Clusters } \\
\hline Musculoskeletal conditions & $\begin{array}{c}-0.184^{* * *} \\
{[-0.212,-0.156]}\end{array}$ & $\begin{array}{c}0.034^{*} \\
{[-0.005,0.072]}\end{array}$ & $\begin{array}{c}0.100 \\
{[-0.029,0.228]}\end{array}$ \\
\hline Mental health conditions & $\begin{array}{c}-0.128^{* * *} \\
{[-0.159,-0.097]}\end{array}$ & $\begin{array}{c}0.003 \\
{[-0.041,0.047]}\end{array}$ & $\begin{array}{c}0.009 \\
{[-0.115,0.132]}\end{array}$ \\
\hline CVD \& diabetes conditions & $\begin{array}{c}-0.060^{* * *} \\
{[-0.081,-0.040]}\end{array}$ & $\begin{array}{c}-0.050^{* * *} \\
{[-0.084,-0.015]}\end{array}$ & $\begin{array}{c}-0.147^{* * *} \\
{[-0.241,-0.053]}\end{array}$ \\
\hline Neurological \& sensory conditions & $\begin{array}{c}-0.003 \\
{[-0.032,0.026]}\end{array}$ & $\begin{array}{c}-0.004 \\
{[-0.040,0.033]}\end{array}$ & $\begin{array}{c}-0.011 \\
{[-0.115,0.092]}\end{array}$ \\
\hline Sample size & 109032 & 359284 & 359284 \\
\hline
\end{tabular}

Notes: OLS figures in column (1) are coefficient estimates on age completed full-time education using only the cohorts born prior to the reform (1 September 1957) and individuals who completed full-time education $\leq$ aged 16 years. OLS figures in column (2) are coefficient estimates on a binary variable indicating whether the individual was born after 1 September 1957 (treatment indicator). 2SLS figures in column (3) are coefficient estimates on age completed full-time education. Control variables include a linear function of month-year of birth, wave number, month of birth (Jan-Dec), and interactions between month-of-birth dummies and the treatment indicator. The condition cluster variables are predicted scores from a principal-components factor analysis with orthogonal rotation of the 17 condition dummy variables. Each condition cluster score has a mean of zero and a standard deviation of one. $95 \%$ confidence intervals are presented in brackets; calculated allowing for clustering at the month-year of birth level. *, ** and *** signify $p$-values less than $0.10,0.05$ and 0.01 , respectively. 
Table 2:

ROSLA Reform: Estimates using Different Bandwidths

\begin{tabular}{|c|c|c|c|c|c|}
\hline & $\begin{array}{l}\text { 36-month } \\
\text { window }\end{array}$ & $\begin{array}{l}\text { 48-month } \\
\text { window }\end{array}$ & $\begin{array}{l}\text { 60-month } \\
\text { window }\end{array}$ & $\begin{array}{l}\text { 72-month } \\
\text { window }\end{array}$ & $\begin{array}{l}\text { 84-month } \\
\text { window }\end{array}$ \\
\hline \multicolumn{6}{|l|}{ Summary Measures } \\
\hline \multirow[t]{2}{*}{ Chronic condition of any type } & -0.011 & 0.013 & 0.005 & 0.006 & 0.009 \\
\hline & {$[-0.046,0.024]$} & {$[-0.035,0.061]$} & {$[-0.047,0.056]$} & {$[-0.033,0.045]$} & {$[-0.033,0.052]$} \\
\hline \multirow[t]{2}{*}{ Limiting chronic condition } & -0.006 & 0.018 & -0.001 & 0.007 & 0.001 \\
\hline & {$[-0.037,0.025]$} & {$[-0.022,0.058]$} & {$[-0.044,0.042]$} & {$[-0.034,0.048]$} & {$[-0.038,0.039]$} \\
\hline \multirow[t]{2}{*}{ Number of chronic conditions } & 0.000 & 0.064 & 0.019 & 0.052 & 0.082 \\
\hline & {$[-0.119,0.120]$} & {$[-0.074,0.203]$} & {$[-0.108,0.146]$} & {$[-0.065,0.170]$} & {$[-0.035,0.200]$} \\
\hline \multicolumn{6}{|l|}{ Condition Clusters } \\
\hline \multirow[t]{2}{*}{ Musculoskeletal condition } & $0.077^{*}$ & $0.141^{* *}$ & 0.100 & 0.091 & $0.132^{* *}$ \\
\hline & {$[-0.010,0.164]$} & {$[0.029,0.253]$} & {$[-0.029,0.228]$} & {$[-0.028,0.209]$} & {$[0.014,0.251]$} \\
\hline \multirow[t]{2}{*}{ Mental health conditions } & $0.095^{* * *}$ & 0.023 & 0.009 & 0.008 & -0.016 \\
\hline & {$[0.061,0.130]$} & {$[-0.087,0.132]$} & {$[-0.115,0.132]$} & {$[-0.084,0.100]$} & {$[-0.124,0.092]$} \\
\hline \multirow[t]{2}{*}{ CVD \& diabetes conditions } & $-0.187^{* * *}$ & $-0.171^{* * *}$ & $-0.147^{* * *}$ & $-0.082^{*}$ & $-0.081^{*}$ \\
\hline & {$[-0.274,-0.099]$} & {$[-0.258,-0.084]$} & {$[-0.241,-0.053]$} & {$[-0.175,0.011]$} & {$[-0.170,0.009]$} \\
\hline \multirow[t]{2}{*}{ Neurological \& sensory disorders } & $-0.103^{*}$ & -0.002 & -0.011 & -0.000 & -0.002 \\
\hline & {$[-0.207,0.001]$} & {$[-0.120,0.116]$} & {$[-0.115,0.092]$} & {$[-0.090,0.089]$} & {$[-0.096,0.091]$} \\
\hline Sample size & 216877 & 288179 & 359284 & 430745 & 504007 \\
\hline
\end{tabular}

Notes: Figures are 2SLS coefficient estimates on age completed full-time education. See notes to Table 1 for descriptions of included control variables, and definitions of chronic condition outcomes. 95\% confidence intervals are presented in brackets; calculated allowing for clustering at the month-year of birth level. *,** and $* * *$ signify $p$-values less than $0.10,0.05$ and 0.01 , respectively. 
Table 3:

Exploring Heterogeneity in Impacts of Reforms on CVD \& Diabetes Cluster

\begin{tabular}{|c|c|c|}
\hline & $\begin{array}{l}\text { ROSLA } \\
\text { (1) }\end{array}$ & $\begin{array}{c}\text { Education Expansion } \\
\text { (2) }\end{array}$ \\
\hline \multicolumn{3}{|l|}{ Gender } \\
\hline \multirow[t]{2}{*}{ Main reform effect } & $-0.041^{* *}$ & $-0.053^{* *}$ \\
\hline & {$[-0.078,-0.004]$} & {$[-0.103,-0.004]$} \\
\hline \multirow[t]{2}{*}{ Male interaction effect } & $-0.018^{*}$ & $-0.030^{* *}$ \\
\hline & {$[-0.040,0.003]$} & {$[-0.058,-0.002]$} \\
\hline \multicolumn{3}{|l|}{ Age } \\
\hline \multirow[t]{2}{*}{ Main reform effect } & $-0.049^{* * *}$ & $-0.073^{* * *}$ \\
\hline & {$[-0.084,-0.015]$} & {$[-0.126,-0.019]$} \\
\hline \multirow{2}{*}{ Linear age interaction effect } & -0.003 & -0.002 \\
\hline & {$[-0.007,0.002]$} & {$[-0.010,0.005]$} \\
\hline Sample size & 359284 & 424925 \\
\hline \multicolumn{3}{|c|}{$\begin{array}{l}\text { Notes: Column (1) reports results based on expansions of the regression from column (2) } \\
\text { in Table } 1 \text {. Column (2) reports results based on expansions of the regression from column } \\
\text { (2) in Table 5. See the respective table notes for list of included control variables. The 'main } \\
\text { reform effect' rows in column (1) provide the estimated coefficients on a binary variable } \\
\text { indicating whether the individual was born after } 1 \text { September } 1957 \text {. The 'main reform effect } \\
\text { rows in column (2) provide the estimated coefficients on average age completed full time } \\
\text { education for an individual's cohort. The male interaction effect is the estimated coefficient } \\
\text { on reform variable * male. The age interaction effect is the estimated coefficient on reform } \\
\text { variable } * \text { demeaned age. } 95 \% \text { confidence intervals are presented in brackets; calculated } \\
\text { allowing for clustering at the month-year of birth level. *, ** and *** signify } p \text {-values less } \\
\text { than } 0.10,0.05 \text { and } 0.01 \text {, respectively. }\end{array}$} \\
\hline
\end{tabular}


Table 4:

ROSLA Reform: Estimates of the Impact of Age Completed Full-Time Education on 17 Chronic Condition Categories

\begin{tabular}{|c|c|c|c|}
\hline & $\begin{array}{c}\text { OLS } \\
\text { Age completed } \\
\text { education (1) }\end{array}$ & $\begin{array}{c}\text { OLS } \\
\text { Affected by } \\
\text { reform (2) }\end{array}$ & $\begin{array}{c}\text { 2SLS } \\
\text { Age completed } \\
\text { education (3) }\end{array}$ \\
\hline \multirow[t]{2}{*}{ Heart, blood pressure or blood circulation problems } & $-0.033^{* * *}$ & -0.006 & -0.017 \\
\hline & {$[-0.039,-0.027]$} & {$[-0.024,0.013]$} & {$[-0.066,0.033]$} \\
\hline \multirow[t]{2}{*}{ Problems or disabilities with back or neck } & $-0.052^{* * *}$ & 0.008 & 0.023 \\
\hline & {$[-0.060,-0.044]$} & {$[-0.009,0.024]$} & {$[-0.029,0.074]$} \\
\hline \multirow[t]{2}{*}{ Problems or disabilities with legs or feet } & $-0.053^{* * *}$ & 0.004 & 0.012 \\
\hline & {$[-0.061,-0.045]$} & {$[-0.005,0.013]$} & {$[-0.015,0.038]$} \\
\hline \multirow[t]{2}{*}{ Problems or disabilities with arms or hands } & $-0.043^{* * *}$ & 0.002 & 0.005 \\
\hline & {$[-0.051,-0.035]$} & {$[-0.007,0.010]$} & {$[-0.021,0.030]$} \\
\hline \multirow[t]{2}{*}{ Chest or breathing problems, asthma, bronchitis } & $-0.029^{* * *}$ & 0.006 & 0.019 \\
\hline & {$[-0.034,-0.025]$} & {$[-0.005,0.017]$} & {$[-0.013,0.051]$} \\
\hline \multirow[t]{2}{*}{ Depression, bad nerves or anxiety } & $-0.034^{* * *}$ & 0.002 & 0.005 \\
\hline & {$[-0.041,-0.028]$} & {$[-0.008,0.011]$} & {$[-0.022,0.032]$} \\
\hline \multirow[t]{2}{*}{ Other health problems or disabilities } & $-0.012^{* * *}$ & -0.006 & -0.018 \\
\hline & {$[-0.017,-0.006]$} & {$[-0.019,0.006]$} & {$[-0.056,0.020]$} \\
\hline \multirow[t]{2}{*}{ Stomach, liver, kidney or digestive problems } & $-0.024^{* * *}$ & 0.002 & 0.006 \\
\hline & {$[-0.029,-0.019]$} & {$[-0.004,0.008]$} & {$[-0.011,0.023]$} \\
\hline \multirow[t]{2}{*}{ Diabetes } & $-0.007^{* * *}$ & $-0.012^{* * *}$ & $-0.036^{* * *}$ \\
\hline & {$[-0.012,-0.002]$} & {$[-0.018,-0.007]$} & {$[-0.058,-0.014]$} \\
\hline \multirow[t]{2}{*}{ Severe disfigurements, skin conditions, allergies } & $-0.011^{* * *}$ & 0.004 & 0.013 \\
\hline & {$[-0.015,-0.007]$} & {$[-0.002,0.010]$} & {$[-0.004,0.029]$} \\
\hline \multirow[t]{2}{*}{ Mental illness, phobias, other nervous disorders } & $-0.020^{* * *}$ & 0.000 & 0.000 \\
\hline & {$[-0.025,-0.015]$} & {$[-0.006,0.006]$} & {$[-0.016,0.016]$} \\
\hline \multirow[t]{2}{*}{ Difficulty in hearing } & $-0.013^{* * *}$ & -0.003 & -0.009 \\
\hline & {$[-0.017,-0.008]$} & {$[-0.007,0.001]$} & {$[-0.021,0.002]$} \\
\hline \multirow[t]{2}{*}{ Progressive illness } & $-0.005^{* * *}$ & $0.004^{* *}$ & $0.012^{* * *}$ \\
\hline & {$[-0.008,-0.002]$} & {$[0.001,0.007]$} & {$[0.003,0.022]$} \\
\hline \multirow[t]{2}{*}{ Difficulty in seeing } & $-0.008^{* * *}$ & 0.003 & 0.009 \\
\hline & {$[-0.010,-0.005]$} & {$[-0.002,0.008]$} & {$[-0.006,0.024]$} \\
\hline \multirow[t]{2}{*}{ Epilepsy } & -0.001 & 0.002 & 0.005 \\
\hline & {$[-0.003,0.002]$} & {$[-0.003,0.007]$} & {$[-0.010,0.020]$} \\
\hline \multirow[t]{2}{*}{ Severe or specific learning difficulties } & -0.001 & $-0.004^{* * *}$ & $-0.011^{* * *}$ \\
\hline & {$[-0.003,0.000]$} & {$[-0.006,-0.002]$} & {$[-0.017,-0.006]$} \\
\hline \multirow[t]{2}{*}{ Speech impediment } & $-0.001^{*}$ & 0.001 & 0.003 \\
\hline & {$[-0.003,0.000]$} & {$[-0.002,0.004]$} & {$[-0.005,0.011]$} \\
\hline Sample size & 109032 & 359284 & 359284 \\
\hline
\end{tabular}

Notes: OLS figures in column (1) are coefficient estimates on age completed full-time education using only the cohorts born prior to the reform (1 September 1957) and individuals who completed full-time education $\leq$ aged 16 years. OLS figures in column (2) are coefficient estimates on a binary variable indicating whether the individual was born after 1 September 1957 (treatment indicator). 2SLS figures in column (3) are coefficient estimates on age completed full-time education. Control variables include a linear function of month-year of birth, a linear function of month-year of birth interacted with the treatment indicator, a third-order polynomial in age, and dummy variables for gender, year of survey (2001-2015), quarter of survey, wave number, month of birth (Jan-Dec), and interactions between month-of-birth dummies and the treatment indicator. 95\% confidence intervals are presented in brackets; calculated allowing for clustering at the month-year of birth level. *,** and *** signify $p$-values less than $0.10,0.05$ and 0.01 , respectively. 
Table 5:

Education Expansion Reform: Estimates of the Impact of Age Completed Full-Time Education on Chronic Condition Summary Measures

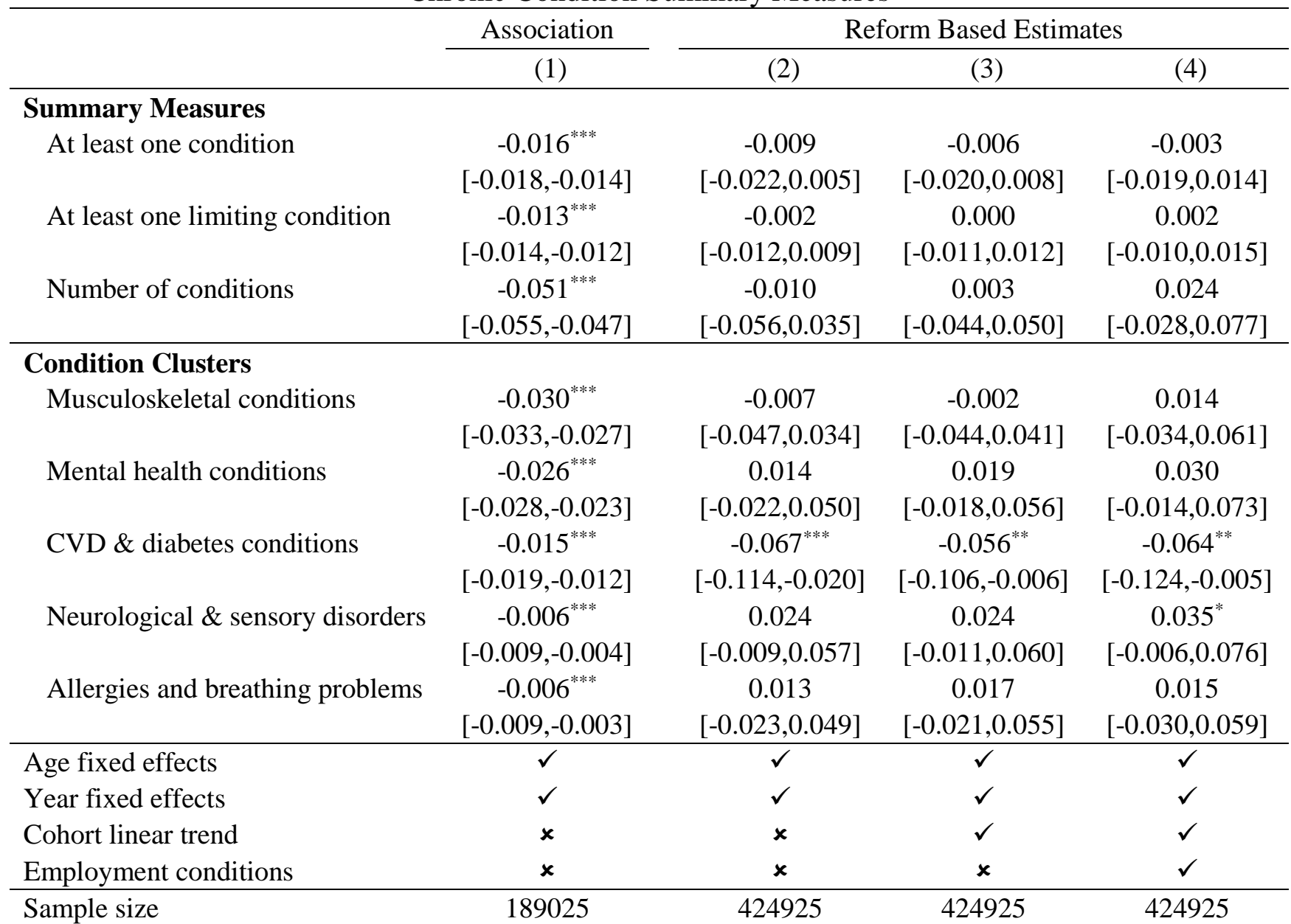

Notes: The figures in column (1) are coefficient estimates on age completed full-time education using only the cohorts born prior to 1970. The figures in columns (2) to (4) are coefficient estimates on mean age completed full time education by monthyear of birth. Control variables all regressions include dummy variables for age surveyed, gender, year of survey, quarter of survey, month of birth, and wave number. The national unemployment rate at age 18 is an additional control variable in column (4). The condition cluster variables are predicted scores from a principal-components factor analysis with orthogonal rotation of the 17 condition dummy variables. Each condition cluster score has a mean of zero and a standard deviation of one. 95\% confidence intervals are presented in brackets; calculated allowing for clustering at the month-year of birth level. *, ** and *** signify $p$-values less than $0.10,0.05$ and 0.01 , respectively. 
Table 6:

Education Expansion Reform: Estimates of the Impact of Age Completed Full-Time Education on 17 Chronic Condition Categories

\begin{tabular}{|c|c|c|}
\hline & $\begin{array}{c}\text { Association } \\
\text { (1) }\end{array}$ & $\begin{array}{l}\text { Reform } \\
\text { (2) }\end{array}$ \\
\hline \multirow[t]{2}{*}{ Heart, blood pressure or blood circulation problems } & $-0.005^{* * *}$ & -0.001 \\
\hline & {$[-0.005,-0.004]$} & {$[-0.007,0.006]$} \\
\hline \multirow[t]{2}{*}{ Problems or disabilities with back or neck } & $-0.008^{* * *}$ & -0.001 \\
\hline & {$[-0.009,-0.007]$} & {$[-0.011,0.010]$} \\
\hline \multirow[t]{2}{*}{ Problems or disabilities with legs or feet } & $-0.007^{* * *}$ & 0.002 \\
\hline & {$[-0.008,-0.006]$} & {$[-0.006,0.010]$} \\
\hline \multirow[t]{2}{*}{ Problems or disabilities with arms or hands } & $-0.005^{* * *}$ & -0.004 \\
\hline & {$[-0.006,-0.005]$} & {$[-0.011,0.004]$} \\
\hline \multirow[t]{2}{*}{ Chest or breathing problems, asthma, bronchitis } & $-0.003^{* * *}$ & 0.001 \\
\hline & {$[-0.004,-0.002]$} & {$[-0.008,0.010]$} \\
\hline \multirow[t]{2}{*}{ Depression, bad nerves or anxiety } & $-0.007^{* * *}$ & 0.000 \\
\hline & {$[-0.008,-0.006]$} & {$[-0.008,0.009]$} \\
\hline \multirow[t]{2}{*}{ Other health problems or disabilities } & $-0.002^{* * *}$ & -0.005 \\
\hline & {$[-0.003,-0.001]$} & {$[-0.012,0.003]$} \\
\hline \multirow[t]{2}{*}{ Stomach, liver, kidney or digestive problems } & $-0.003^{* * *}$ & -0.005 \\
\hline & {$[-0.003,-0.002]$} & {$[-0.011,0.002]$} \\
\hline \multirow[t]{2}{*}{ Diabetes } & $-0.002^{* * *}$ & $-0.009^{* *}$ \\
\hline & {$[-0.002,-0.001]$} & {$[-0.016,-0.002]$} \\
\hline \multirow[t]{2}{*}{ Severe disfigurements, skin conditions, allergies } & $-0.001^{* * *}$ & 0.004 \\
\hline & {$[-0.002,-0.001]$} & {$[-0.001,0.009]$} \\
\hline \multirow[t]{2}{*}{ Mental illness, phobias, other nervous disorders } & $-0.004^{* * *}$ & 0.002 \\
\hline & {$[-0.005,-0.004]$} & {$[-0.003,0.007]$} \\
\hline \multirow[t]{2}{*}{ Difficulty in hearing } & $-0.001^{* * *}$ & 0.000 \\
\hline & {$[-0.002,-0.001]$} & {$[-0.003,0.004]$} \\
\hline \multirow[t]{2}{*}{ Progressive illness } & $-0.001^{* * *}$ & -0.000 \\
\hline & {$[-0.001,-0.001]$} & {$[-0.005,0.004]$} \\
\hline \multirow[t]{2}{*}{ Difficulty in seeing } & $-0.001^{* * *}$ & -0.003 \\
\hline & {$[-0.001,-0.001]$} & {$[-0.006,0.001]$} \\
\hline \multirow[t]{2}{*}{ Epilepsy } & $-0.001^{* * *}$ & 0.002 \\
\hline & {$[-0.001,-0.000]$} & {$[-0.001,0.006]$} \\
\hline \multirow[t]{2}{*}{ Severe or specific learning difficulties } & $-0.001^{* * *}$ & 0.001 \\
\hline & {$[-0.001,-0.001]$} & {$[-0.002,0.005]$} \\
\hline \multirow[t]{2}{*}{ Speech impediment } & $-0.000^{* * *}$ & $0.002^{* *}$ \\
\hline & {$[-0.001,-0.000]$} & {$[0.000,0.003]$} \\
\hline Sample size & 189025 & 424925 \\
\hline
\end{tabular}

Notes: The figures in column (1) are coefficient estimates on age completed full-time education using only the cohorts born prior to 1970. The figures in column (2) are coefficient estimates on average age completed full time education for an individual's month-year cohort. Control variables include dummy variables for age surveyed, gender, year of survey, quarter of survey, month of birth, and wave number. 95\% confidence intervals are presented in brackets; calculated allowing for clustering at the month-year of birth level. *,** and $* * *$ signify $p$-values less than $0.10,0.05$ and 0.01 , respectively. 


\section{APPENDIX}

Appendix Figure A1:

Prevalence of Leaving School $\geq 16$ years for Months-of-Birth around the ROSLA Reform Cutoff

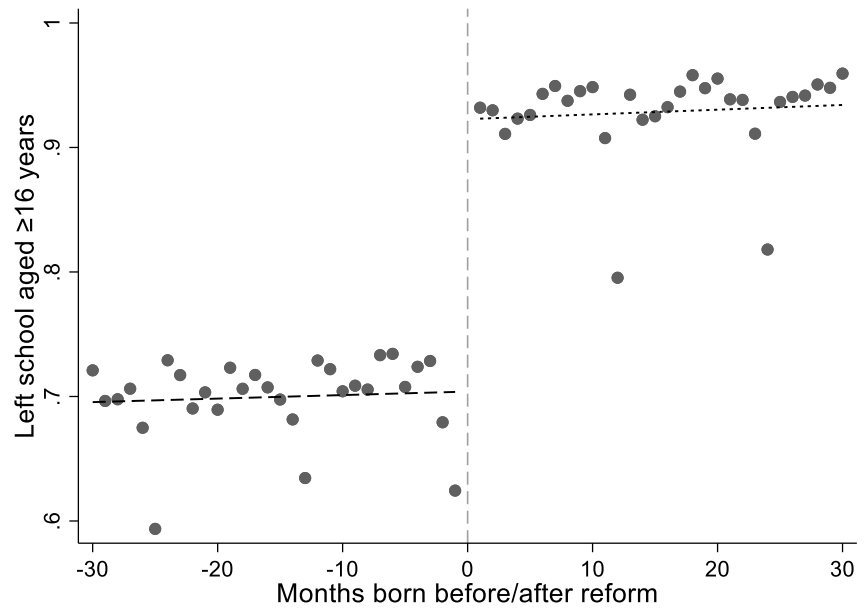

Notes: Each point represents the sample mean for a month-year of birth. Linear regression predictions of education given month of birth are given separately for months before and after reform.

Appendix Figure A2:

Prevalence of Diabetes for Months-of-Birth around the ROSLA Reform Cutoff

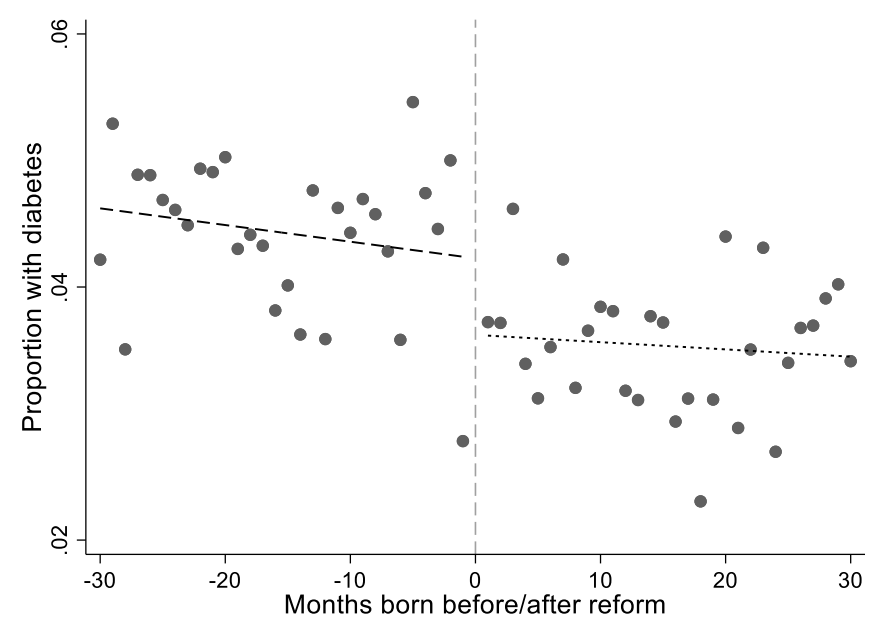

Notes: Each point represents the sample mean for a month-year of birth. Linear regression predictions of diabetes given month of birth are given separately for months before and after reform.

Appendix Figure A3: 
Prevalence of Diabetes for Months-of-Birth around the Education Expansion Reform

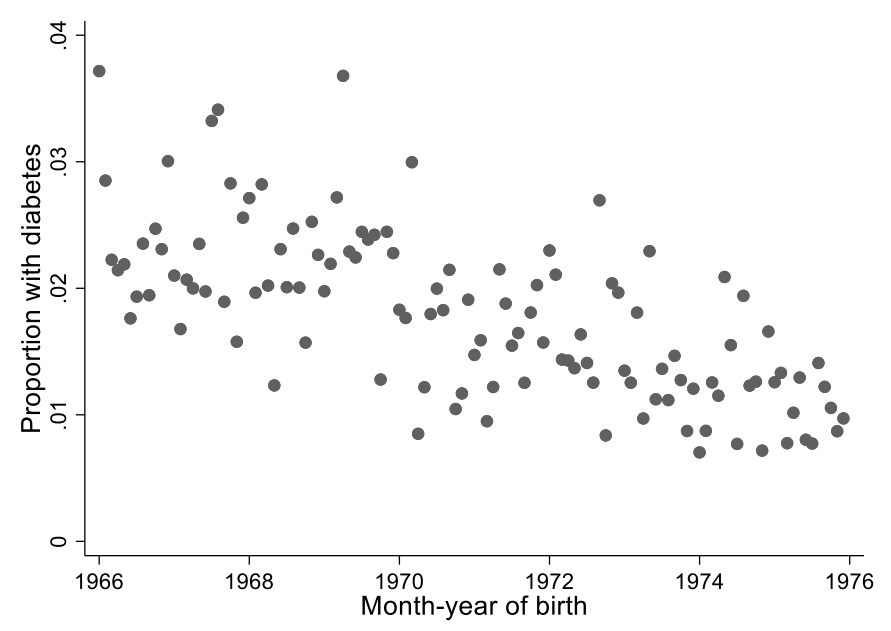

Notes: Each point represents the sample mean for a month-year of birth. 
Appendix Table A1: Summary Statistics for each Reform Estimation Sample

\begin{tabular}{|c|c|c|}
\hline & $\begin{array}{l}\text { ROSLA } \\
\text { Sample }\end{array}$ & $\begin{array}{c}\text { Education } \\
\text { Expansion } \\
\text { Sample }\end{array}$ \\
\hline Male & 0.478 & 0.464 \\
\hline Age & 50.08 & 39.74 \\
\hline Married or cohabitating & 0.762 & 0.764 \\
\hline Non-white & 0.018 & 0.048 \\
\hline Age completed full-time education & 17.13 & 17.94 \\
\hline Employee & 0.689 & 0.717 \\
\hline Self-employed & 0.120 & 0.113 \\
\hline Unemployed & 0.028 & 0.035 \\
\hline Chronic condition of any type & 0.364 & 0.265 \\
\hline Limiting chronic condition & 0.131 & 0.085 \\
\hline Number of chronic conditions & 0.834 & 0.525 \\
\hline Heart, blood pressure or blood circulation problems & 0.113 & 0.044 \\
\hline Problems or disabilities with back or neck & 0.111 & 0.067 \\
\hline Problems or disabilities with legs or feet & 0.105 & 0.055 \\
\hline Problems or disabilities with arms or hands & 0.079 & 0.039 \\
\hline Chest or breathing problems, asthma, bronchitis & 0.074 & 0.066 \\
\hline Depression, bad nerves or anxiety & 0.060 & 0.054 \\
\hline Other health problems or disabilities & 0.059 & 0.045 \\
\hline Stomach, liver, kidney or digestive problems & 0.053 & 0.036 \\
\hline Diabetes & 0.040 & 0.018 \\
\hline Severe disfigurements, skin conditions, allergies & 0.031 & 0.026 \\
\hline Mental illness, phobias, panics, other nervous disorders & 0.028 & 0.026 \\
\hline Difficulty in hearing & 0.025 & 0.012 \\
\hline Progressive illness (e.g. cancer, MS, AIDS, Parkinson's) & 0.022 & 0.013 \\
\hline Difficulty in seeing & 0.017 & 0.009 \\
\hline Epilepsy & 0.008 & 0.008 \\
\hline Severe or specific learning difficulties & 0.007 & 0.006 \\
\hline Speech impediment & 0.003 & 0.002 \\
\hline Survey years included & 2001-2016 & 2006-2016 \\
\hline Years of birth included & 1955-1960 & 1966-1975 \\
\hline Age range & 41-61 & $30-50$ \\
\hline Number of individuals & 105,193 & 140,461 \\
\hline Number of observations & 359,284 & 424,925 \\
\hline \multicolumn{3}{|c|}{$\begin{array}{l}\text { Notes: Figures are sample means of variables from the UK Quarterly Labour Force Survey. A chroni } \\
\text { condition is defined as a health problem or disability that is expected to last for more than one year. } \\
\text { limiting chronic condition is defined as a chronic condition that limits ability to carry out normal day-to } \\
\text { day activities, affects the kind of paid work that respondents might do, and affects the amount of pai } \\
\text { work that respondents might do. The } 17 \text { chronic condition categories presented are not mutuall } \\
\text { exclusive. }\end{array}$} \\
\hline
\end{tabular}


Appendix Table A2: Within-Individual Across-Wave Variation in Reported Chronic Health Conditions

\begin{tabular}{|c|c|c|c|c|}
\hline & $\begin{array}{c}\% \text { who } \\
\text { always report } \\
\text { condition } \\
(1)\end{array}$ & $\begin{array}{c}\% \text { with } \\
\mathrm{H}_{t}=\text { yes } \\
\mathrm{H}_{t+1}=\text { no } \\
(2)\end{array}$ & $\begin{array}{c}\% \text { with } \\
\mathrm{H}_{t}=\text { no } \\
\mathrm{H}_{t+1}=\text { yes } \\
(3)\end{array}$ & $\begin{array}{c}\text { Ratio } \\
(3) /(2) \\
(4)\end{array}$ \\
\hline Diabetes & 75 & 9 & 21 & 2.41 \\
\hline Epilepsy & 70 & 14 & 23 & 1.66 \\
\hline Severe or specific learning difficulties & 42 & 20 & 48 & 2.36 \\
\hline Speech impediment & 41 & 21 & 47 & 2.27 \\
\hline Problems or disabilities with legs or feet & 51 & 21 & 38 & 1.78 \\
\hline Problems or disabilities with arms or hands & 52 & 21 & 36 & 1.71 \\
\hline Chest or breathing problems, asthma, bronchitis & 55 & 22 & 34 & 1.52 \\
\hline Difficulty in hearing & 42 & 23 & 46 & 2.02 \\
\hline Depression, bad nerves or anxiety & 48 & 23 & 40 & 1.72 \\
\hline Mental illness, phobias, other nervous disorders & 46 & 24 & 40 & 1.65 \\
\hline Problems or disabilities with back or neck & 52 & 24 & 35 & 1.47 \\
\hline Heart, blood pressure or blood circulation problems & 52 & 25 & 36 & 1.45 \\
\hline Stomach, liver, kidney or digestive problems & 43 & 29 & 41 & 1.44 \\
\hline Severe disfigurements, skin conditions, allergies & 33 & 32 & 49 & 1.57 \\
\hline Difficulty in seeing & 38 & 32 & 43 & 1.33 \\
\hline Progressive illness & 44 & 32 & 36 & 1.14 \\
\hline Other health problems or disabilities & 29 & 41 & 48 & 1.17 \\
\hline
\end{tabular}

Notes: For each condition, reported percentages are based on the sample who 'ever' reported the condition (i.e. at least once across the 5 waves). $\mathrm{H}_{t}=$ yes means that in wave $t$, individual $i$ reported the health condition. $\mathrm{H}_{t}=$ no means that in wave $t$, individual $i$ did not report the health condition. Sample includes all individuals in years 2001-2016, born in the UK, who were aged 40-60. This sample includes 1059890 health observations from 211978 individuals. 


\section{Appendix Table A3:}

Tetrachoric correlations for the 17 Chronic Condition Categories

\begin{tabular}{|c|c|c|c|c|c|c|c|c|c|c|c|c|c|c|c|c|c|c|}
\hline & & 1 & 2 & 3 & 4 & 5 & 6 & 7 & 8 & 9 & 10 & 11 & 12 & 13 & 14 & 15 & 16 & 17 \\
\hline 1 & Problems or disabilities with back or neck & 1 & & & & & & & & & & & & & & & & \\
\hline 2 & Problems or disabilities with legs or feet & 0.78 & 1 & & & & & & & & & & & & & & & \\
\hline 3 & Heart, blood pressure or blood circulation problems & 0.39 & 0.45 & 1 & & & & & & & & & & & & & & \\
\hline 4 & Problems or disabilities with arms or hands & 0.78 & 0.84 & 0.42 & 1 & & & & & & & & & & & & & \\
\hline 5 & Chest or breathing problems, asthma, bronchitis & 0.43 & 0.44 & 0.36 & 0.44 & 1 & & & & & & & & & & & & \\
\hline 6 & Depression, bad nerves or anxiety & 0.58 & 0.58 & 0.43 & 0.57 & 0.47 & 1 & & & & & & & & & & & \\
\hline 7 & Other health problems or disabilities & 0.30 & 0.33 & 0.25 & 0.33 & 0.23 & 0.34 & 1 & & & & & & & & & & \\
\hline 8 & Stomach, liver, kidney or digestive problems & 0.52 & 0.52 & 0.42 & 0.52 & 0.43 & 0.56 & 0.31 & 1 & & & & & & & & & \\
\hline 9 & Diabetes & 0.22 & 0.32 & 0.48 & 0.28 & 0.23 & 0.31 & 0.16 & 0.29 & 1 & & & & & & & & \\
\hline 10 & Mental illness, phobias, other nervous disorders & 0.49 & 0.49 & 0.35 & 0.48 & 0.40 & 0.84 & 0.27 & 0.48 & 0.24 & 1 & & & & & & & \\
\hline 11 & Severe disfigurements, skin conditions, allergies & 0.49 & 0.50 & 0.37 & 0.51 & 0.50 & 0.49 & 0.30 & 0.46 & 0.21 & 0.45 & 1 & & & & & & \\
\hline 12 & Difficulty in hearing & 0.44 & 0.45 & 0.33 & 0.45 & 0.35 & 0.44 & 0.28 & 0.39 & 0.23 & 0.41 & 0.38 & 1 & & & & & \\
\hline 13 & Progressive illness (e.g. cancer, MS, AIDS) & 0.34 & 0.40 & 0.22 & 0.41 & 0.26 & 0.35 & 0.15 & 0.33 & 0.15 & 0.28 & 0.30 & 0.25 & 1 & & & & \\
\hline 14 & Difficulty in seeing & 0.41 & 0.46 & 0.36 & 0.45 & 0.32 & 0.46 & 0.27 & 0.41 & 0.35 & 0.41 & 0.36 & 0.45 & 0.37 & 1 & & & \\
\hline 15 & Epilepsy & 0.22 & 0.30 & 0.19 & 0.27 & 0.19 & 0.33 & 0.21 & 0.23 & 0.08 & 0.32 & 0.19 & 0.24 & 0.21 & 0.31 & 1 & & \\
\hline 16 & Severe or specific learning difficulties & 0.31 & 0.38 & 0.22 & 0.32 & 0.27 & 0.45 & 0.23 & 0.30 & 0.21 & 0.48 & 0.31 & 0.40 & 0.16 & 0.37 & 0.45 & 1 & \\
\hline 17 & Speech impediment & 0.37 & 0.51 & 0.35 & 0.47 & 0.31 & 0.46 & 0.34 & 0.36 & 0.15 & 0.47 & 0.33 & 0.45 & 0.45 & 0.51 & 0.43 & 0.62 & 1 \\
\hline
\end{tabular}


Appendix Table A4:

ROSLA Reform: Scoring Coefficients for the Predicted Scores for the four Condition Clusters

\begin{tabular}{lcccc}
\hline & $\begin{array}{c}\text { Musculo- } \\
\text { skeletal } \\
\text { condition }\end{array}$ & $\begin{array}{c}\text { Mental } \\
\text { health } \\
\text { condition }\end{array}$ & $\begin{array}{c}\text { CVD \& } \\
\text { diabetes }\end{array}$ & $\begin{array}{c}\text { Neurological } \\
\text { d sensory } \\
\text { disorders }\end{array}$ \\
\hline Heart, blood pressure or blood circulation problems & -0.009 & -0.026 & $\mathbf{0 . 4 9 9}$ & -0.048 \\
Problems or disabilities with back or neck & $\mathbf{0 . 3 7 5}$ & -0.055 & -0.121 & -0.073 \\
Problems or disabilities with legs or feet & $\mathbf{0 . 3 8 9}$ & -0.114 & -0.061 & -0.014 \\
Problems or disabilities with arms or hands & $\mathbf{0 . 4 0 2}$ & -0.116 & -0.096 & -0.028 \\
Chest or breathing problems, asthma, bronchitis & 0.048 & 0.149 & 0.114 & -0.099 \\
Depression, bad nerves or anxiety & -0.061 & $\mathbf{0 . 5 0 0}$ & -0.047 & -0.059 \\
Other health problems or disabilities & 0.037 & 0.021 & 0.102 & 0.051 \\
Stomach, liver, kidney or digestive problems & 0.065 & 0.152 & 0.114 & -0.069 \\
Diabetes & -0.125 & -0.086 & $\mathbf{0 . 6 7 3}$ & -0.028 \\
Severe disfigurements, skin conditions, allergies & 0.076 & 0.139 & 0.042 & -0.076 \\
Mental illness, phobias, panics, nervous disorders & -0.154 & $\mathbf{0 . 5 8 9}$ & -0.116 & -0.030 \\
Difficulty in hearing & 0.033 & 0.016 & 0.095 & 0.183 \\
Progressive illness (e.g. cancer, MS, Parkinson's) & 0.138 & -0.122 & -0.024 & 0.187 \\
Difficulty in seeing & -0.005 & -0.060 & 0.230 & 0.269 \\
Epilepsy & -0.015 & 0.000 & -0.070 & $\mathbf{0 . 3 4 7}$ \\
Severe or specific learning difficulties & -0.090 & 0.087 & -0.059 & $\mathbf{0 . 4 7 1}$ \\
Speech impediment & -0.008 & -0.072 & -0.033 & $\mathbf{0 . 5 5 2}$ \\
\hline Notes: The
\end{tabular}

Notes: The coefficients are from a principal-components factor analysis with orthogonal rotation. All coefficients larger than 0.3 are in bold font.

Appendix Table A5:

Education Expansion Reform: Scoring Coefficients for the Predicted Scores for Condition Clusters

\begin{tabular}{|c|c|c|c|c|c|}
\hline & \multicolumn{5}{|c|}{ Allergies } \\
\hline & $\begin{array}{l}\text { Musculo- } \\
\text { skeletal } \\
\text { condition }\end{array}$ & $\begin{array}{l}\text { Mental } \\
\text { health } \\
\text { condition }\end{array}$ & $\begin{array}{c}\& \\
\text { breathing } \\
\text { problems }\end{array}$ & $\begin{array}{c}\text { Neurological } \\
\& \text { sensory } \\
\text { disorders }\end{array}$ & $\begin{array}{l}\text { CVD \& } \\
\text { diabetes }\end{array}$ \\
\hline Heart, blood pressure or blood circulation problems & -0.014 & 0.018 & 0.061 & -0.051 & 0.491 \\
\hline Problems or disabilities with back or neck & 0.386 & -0.022 & -0.019 & -0.096 & -0.095 \\
\hline Problems or disabilities with legs or feet & 0.424 & -0.053 & -0.075 & -0.051 & -0.045 \\
\hline Problems or disabilities with arms or hands & 0.428 & -0.072 & -0.077 & -0.036 & -0.061 \\
\hline Chest or breathing problems, asthma, bronchitis & -0.076 & -0.054 & 0.625 & -0.054 & -0.044 \\
\hline Depression, bad nerves or anxiety & -0.020 & 0.513 & -0.058 & -0.080 & 0.006 \\
\hline Other health problems or disabilities & 0.004 & 0.040 & 0.076 & 0.016 & 0.155 \\
\hline Stomach, liver, kidney or digestive problems & 0.047 & 0.079 & 0.180 & -0.065 & 0.115 \\
\hline Diabetes & -0.085 & -0.024 & -0.103 & -0.030 & 0.704 \\
\hline Severe disfigurements, skin conditions, allergies & -0.032 & -0.069 & 0.582 & 0.012 & -0.079 \\
\hline Mental illness, phobias, panics, nervous disorders & -0.092 & 0.598 & -0.097 & -0.072 & -0.057 \\
\hline Difficulty in hearing & -0.032 & -0.088 & 0.146 & 0.378 & 0.021 \\
\hline Progressive illness (e.g. cancer, MS, Parkinson's) & 0.178 & -0.119 & -0.138 & 0.207 & 0.042 \\
\hline Difficulty in seeing & 0.014 & -0.113 & -0.036 & 0.369 & 0.224 \\
\hline Epilepsy & -0.016 & 0.119 & -0.170 & 0.246 & -0.030 \\
\hline Severe or specific learning difficulties & -0.134 & 0.227 & 0.036 & 0.336 & -0.155 \\
\hline Speech impediment & -0.030 & -0.045 & -0.034 & 0.555 & -0.078 \\
\hline
\end{tabular}

Notes: The coefficients are from a principal-components factor analysis with orthogonal rotation. All coefficients larger than 0.3 are in bold font. 
Appendix Table A6:

Impact of the ROSLA Reform on Educational Attainment

\begin{tabular}{lccccc}
\hline & $\begin{array}{c}\text { Age } \\
\text { Completed } \\
\text { Full-Time } \\
\text { Education }\end{array}$ & $\begin{array}{c}\text { Completed } \\
\text { Aged } \geq 16\end{array}$ & $\begin{array}{c}\text { Completed } \\
\text { Aged } \geq 17\end{array}$ & $\begin{array}{c}\text { Highest } \\
\text { Qualification } \\
\geq \text { GCSE }\end{array}$ & $\begin{array}{c}\text { Highest } \\
\text { Qualification } \\
\geq \text { A-Level }\end{array}$ \\
\hline All Persons & & & & & \\
Estimate & $0.282^{* * *}$ & $0.210^{* * *}$ & 0.017 & $0.045^{* * *}$ & 0.007 \\
& $(0.036)$ & $(0.004)$ & $(0.012)$ & $(0.011)$ & $(0.022)$ \\
F-Statistic & 62.54 & 3200.48 & 2.21 & 16.10 & 0.10 \\
Outcome mean & 17.08 & 0.81 & 0.37 & 0.72 & 0.51 \\
\hline Men Only & & & & & \\
Estimate & $0.231^{*}$ & $0.211^{* * *}$ & -0.002 & $0.040^{* * * *}$ & 0.020 \\
& $(0.124)$ & $(0.015)$ & $(0.022)$ & $(0.009)$ & $(0.019)$ \\
F-Statistic & 3.45 & 206.32 & 0.01 & 18.72 & 1.09 \\
Outcome mean & 17.15 & 0.81 & 0.36 & 0.74 & 0.59 \\
\hline Women Only & & & & & \\
Estimate & $0.331^{* * *}$ & $0.209^{* * *}$ & $0.037^{* * *}$ & $0.050^{* * *}$ & -0.007 \\
& $(0.082)$ & $(0.013)$ & $(0.011)$ & $(0.019)$ & $(0.026)$ \\
F-Statistic & 16.42 & 242.72 & 10.79 & 7.21 & 0.07 \\
Outcome mean & 17.01 & 0.81 & 0.39 & 0.70 & 0.44 \\
\hline
\end{tabular}

Notes: The figures are OLS coefficient estimates on a binary variable indicating whether the individual was born after 1 September 1957 (treatment indicator). Control variables include a linear function of month-year of birth, a linear function of month-year of birth interacted with the treatment indicator, a third-order polynomial in age, and dummy variables for gender, year of survey (2001-2015), quarter of survey, wave number, month of birth (Jan-Dec), and interactions between month-of-birth dummies and the treatment indicator. The estimation sample only includes one report from each individual. Sample sizes for all, men and women equal 105193, 51064 and 54129, respectively. Standard errors clustered at the month-year level. *,** and *** signify p-values less than 0.10, 0.05 and 0.01 , respectively. 
Appendix Table A7:

Endogeneity Test Results from 2SLS ROSLA Reform Regressions

\begin{tabular}{lcc}
\hline & F-Statistic & $p$-value \\
\hline Chronic condition of any type & 17.01 & 0.0001 \\
Limiting chronic condition & 17.99 & 0.0001 \\
Number of chronic conditions & 12.78 & 0.0007 \\
Musculoskeletal conditions & 44.29 & 0.0000 \\
Mental health conditions & 0.857 & 0.3583 \\
CVD \& diabetes conditions & 8.461 & 0.0051 \\
Neurological \& sensory conditions & 0.365 & 0.5478 \\
\hline
\end{tabular}

Notes: Null hypothesis is that 'age completed full-time education' is exogenous (OLS is a consistent estimator). Based on 2SLS specification shown in Table 1, for the sample of individuals who completed full-time education $\leq$ aged 16 years. Test statistics are based on Wooldridge's (1995) robust regression-based test, generated using Stata's post-estimation command 'estat endogenous'.

Appendix Table A8:

Impact of Education on Chronic Conditions: Samples Excluding Proxy Responses

\begin{tabular}{|c|c|c|}
\hline & $\begin{array}{c}\text { ROSLA } \\
(1) \\
\end{array}$ & $\begin{array}{c}\text { Education } \\
\text { Expansion } \\
\text { (2) }\end{array}$ \\
\hline \multicolumn{3}{|l|}{ Summary measures } \\
\hline Chronic condition of any type & $\begin{array}{c}0.012 \\
{[-0.037,0.061]}\end{array}$ & $\begin{array}{c}-0.013 \\
{[-0.028,0.003]}\end{array}$ \\
\hline Limiting chronic condition & $\begin{array}{c}-0.002 \\
{[-0.038,0.034]}\end{array}$ & $\begin{array}{c}-0.003 \\
{[-0.015,0.010]}\end{array}$ \\
\hline Number of chronic conditions & $\begin{array}{c}-0.016 \\
{[-0.154,0.121]}\end{array}$ & $\begin{array}{c}-0.015 \\
{[-0.068,0.039]}\end{array}$ \\
\hline \multicolumn{3}{|l|}{ Condition clusters } \\
\hline Musculoskeletal conditions & $\begin{array}{c}0.098 \\
{[-0.048,0.243]}\end{array}$ & $\begin{array}{c}-0.015 \\
{[-0.065,0.035]}\end{array}$ \\
\hline Mental health conditions & $\begin{array}{c}0.009 \\
{[-0.095,0.114]}\end{array}$ & $\begin{array}{c}0.020 \\
{[-0.029,0.068]}\end{array}$ \\
\hline CVD \& diabetes conditions & $\begin{array}{c}-0.200^{* * *} \\
{[-0.329,-0.072]}\end{array}$ & $\begin{array}{c}-0.077^{* * *} \\
{[-0.122,-0.031]}\end{array}$ \\
\hline Neurological \& sensory conditions & $\begin{array}{c}-0.037 \\
{[-0.144,0.070]}\end{array}$ & $\begin{array}{c}0.025 \\
{[-0.013,0.063]}\end{array}$ \\
\hline Allergies \& breathing problems & - & $\begin{array}{c}0.019 \\
{[-0.024,0.062]}\end{array}$ \\
\hline Sample size & 263720 & 314796 \\
\hline
\end{tabular}

Notes: The estimates are equivalent to those shown in Table 1 (column 3 ) and Table 5 (column

2 ), respectively, but exclude proxy respondents from the estimation samples. 
Appendix Table A9:

Impact of Education on Chronic Conditions: If Reported Health Condition in All Waves

\begin{tabular}{lcc}
\hline & ROSLA & $\begin{array}{c}\text { Education } \\
\text { Expansion } \\
(1)\end{array}$ \\
\hline Summary measures & -0.030 & -0.007 \\
Chronic condition of any type & {$[-0.104,0.044]$} & {$[-0.021,0.008]$} \\
& 0.011 & -0.002 \\
Limiting chronic condition & {$[-0.039,0.061]$} & {$[-0.014,0.011]$} \\
& -0.008 & -0.026 \\
Number of chronic conditions & {$[-0.262,0.245]$} & {$[-0.063,0.010]$} \\
\hline Condition clusters & 0.111 & 0.001 \\
Musculoskeletal conditions & {$[-0.037,0.258]$} & {$[-0.035,0.036]$} \\
& 0.073 & 0.002 \\
Mental health conditions & {$[-0.080,0.226]$} & {$[-0.038,0.041]$} \\
CVD \& diabetes conditions & $-0.317^{* * *}$ & $-0.066 *$ \\
Neurological \& sensory conditions & {$[-0.475,-0.160]$} & {$[-0.108,-0.023]$} \\
& -0.070 & -0.019 \\
Allergies \& breathing problems & {$[-0.156,0.016]$} & {$[-0.057,0.018]$} \\
& - & 0.009 \\
\hline Sample size & & {$[-0.028,0.047]$} \\
\hline
\end{tabular}

Notes: The estimates are equivalent to those shown in Table 1 (column 3) and Table 5 (column 2 ), respectively, but the health condition measures are defined as the individual having the condition in all waves if reported in any wave. 
Appendix Table A10:

Education Expansion Reform: 2SLS Estimates using Alternative Modelling Approaches

\begin{tabular}{lcc}
\hline & $(1)$ & $(2)$ \\
& $\begin{array}{c}\text { Cohort average } \\
\text { age completed } \\
\text { education }\end{array}$ & $\begin{array}{c}\text { Devereux\&Fan } \\
(2011)\end{array}$ \\
\hline Summary measures & -0.010 & -0.008 \\
Chronic condition of any type & {$[-0.025,0.005]$} & {$[-0.032,0.015]$} \\
& -0.002 & 0.002 \\
Limiting chronic condition & {$[-0.014,0.010]$} & {$[-0.013,0.017]$} \\
& -0.012 & 0.016 \\
Number of chronic conditions & {$[-0.062,0.038]$} & {$[-0.049,0.081]$} \\
\hline Condition clusters & -0.007 & 0.006 \\
Musculoskeletal conditions & {$[-0.052,0.038]$} & {$[-0.044,0.056]$} \\
& 0.016 & 0.034 \\
Mental health conditions & {$[-0.024,0.056]$} & {$[-0.019,0.087]$} \\
CVD \& diabetes conditions & $-0.075^{* * *}$ & $-0.063^{* *}$ \\
Neurological \& sensory conditions & {$[-0.129,-0.022]$} & {$[-0.116,-0.010]$} \\
Allergies \& breathing problems & 0.027 & 0.010 \\
& {$[-0.010,0.063]$} & {$[-0.038,0.059]$} \\
Sample size & 0.015 & 0.030 \\
\hline
\end{tabular}

Notes: The figures in column (1) are 2SLS estimates using average age completed full-time education of an individual's cohort as an instrumental variable for own age completed full-time education. The estimation sample and covariate set are the same as used in regressions from Table 5. The figures in column (2) are 2SLS estimates using as instruments dummy variables for being in a cohort born in $1970,71,72,73,74,75$, and an additional dummy variable for being born 1976 or after. Sample includes birth cohort years 1958 to 1982. Covariates include a quartic function of year-of-birth, a quartic function of age, and sex. 95\% confidence intervals are presented in brackets; calculated allowing for clustering at the month of birth level. *,** and *** signify $p$-values less than $0.10,0.05$ and 0.01 , respectively. 